\title{
Article
}

\section{The iMPROVE Study; Design, Dietary Patterns, and Development of a Lifestyle Index in Overweight and Obese Greek Adults}

\author{
Maria Kafyra ${ }^{1,+}$, Ioanna P. Kalafati ${ }^{1,+}$, Efthymia A. Katsareli ${ }^{1}$, Sophia Lambrinou ${ }^{1}$, Iraklis Varlamis ${ }^{2}$ (D), \\ Andriana C. Kaliora ${ }^{1}$ and George V. Dedoussis ${ }^{1, *(D)}$
}

1 Department of Nutrition and Dietetics, School of Health Sciences and Education, Harokopio University of Athens, 17671 Athens, Greece; mariakaf@hua.gr (M.K.); nkalafati@gmail.com (I.P.K.); ekatsa@hotmail.com (E.A.K.); sophialambrinou@gmail.com (S.L.); akaliora@hua.gr (A.C.K.)

2 Department of Informatics and Telematics, School of Digital Technology, Harokopio University of Athens, 17671 Athens, Greece; varlamis@hua.gr

* Correspondence: dedousi@hua.gr; Tel.: +30-2109549179

+ These authors contributed equally to this paper.

check for

updates

Citation: Kafyra, M.; Kalafati, I.P.; Katsareli, E.A.; Lambrinou, S.; Varlamis, I.; Kaliora, A.C.; Dedoussis, G.V. The iMPROVE Study; Design, Dietary Patterns, and Development of a Lifestyle Index in Overweight and Obese Greek Adults. Nutrients 2021 13, 3495. https://doi.org/10.3390/ nu13103495

Academic Editor: Ulrika Ericson

Received: 10 September 2021

Accepted: 30 September 2021

Published: 3 October 2021

Publisher's Note: MDPI stays neutral with regard to jurisdictional claims in published maps and institutional affiliations.

Copyright: (c) 2021 by the authors. Licensee MDPI, Basel, Switzerland. This article is an open access article distributed under the terms and conditions of the Creative Commons Attribution (CC BY) license (https:// creativecommons.org/licenses/by/ $4.0 /)$.
Abstract: Background: Dietary and lifestyle habits constitute a significant contributing factor in the formation of anthropometric and biochemical characteristics of overweight and obese populations. The iMPROVE study recruited overweight and obese Greek adults and investigated the effect of gene-diet interactions on weight management when adhering to a six-month, randomized nutritional trial including two hypocaloric diets of different macronutrient content. The present paper displays the design of the intervention and the baseline findings of the participants' dietary habits and their baseline anthropometric and biochemical characteristics. Methods: Baseline available data for 202 participants were analyzed and patterns were extracted via principal component analysis (PCA) on 69-item Food-Frequency Questionnaires (FFQ). Relationships with indices at baseline were investigated by multivariate linear regressions. A Lifestyle Index of five variables was further constructed. Results: PCA provided 5 dietary patterns. The "Mixed" pattern displayed positive

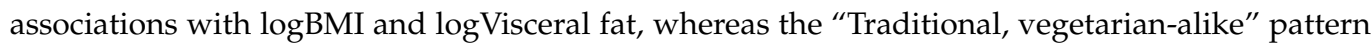
was nominally, negatively associated with body and visceral fat, but positively associated with HDL levels. The Lifestyle Index displayed protective effects in the formation of logBMI and logGlucose levels. Conclusions: Dietary patterns and a Lifestyle Index in overweight and obese, Greek adults highlighted associations between diet, lifestyle, and anthropometric and biochemical indices.

Keywords: overweight; obesity; adults; dietary patterns; lifestyle index; health status; online assessment tool; nutritional intervention; weight management

\section{Introduction}

The past decades have marked a noticeable increase in adult overweight and obesity. Current epidemiological evidence suggests that more than half of the adult in the European population presents a body mass index (BMI) of above $25 \mathrm{~kg} / \mathrm{m}^{2}$ and is, therefore, classified in the category of overweight [1]. Factors relating to increased body weight vary, including genetic predisposition, lifestyle habits, and environmental conditions, as well as their respective interplay.

The role of dietary habits in overweight and obesity development has been extensively studied in populations of various ages and ethnicities [2]. It is widely established that consumption of energy-dense foodstuffs and/or products with high sugar or fat content is positively correlated with increased weight and weight management [3]. Apart from habitual dietary preferences, adherence to specific dietary patterns, such as the Mediterranean or the Western diets, has also been associated with long-term weight management. In their 2017 review, Mu et al. demonstrated that diets rich in fruits and vegetables are correlated 
with lower values of BMI, whereas higher consumption of meats and high-fat products are associated with increased BMI [2]. In the same context, Cena and Calder examined the components of constructing a healthy diet and its relation to general health status. Their 2020 review concluded that diets including fruits, vegetables, and plant-based foods, among others, such as the Mediterranean and Asian diets, reduce the risk of non-communicable diseases (NCDs) development [4].

Additionally, the identification of adherence to specific dietary patterns has been shown to be related to lifestyle parameters, namely depression and sleep characteristics. Li et al. showed that adherence to balanced dietary patterns including whole-grain products, fish, fruit, and vegetables was related to decreased risk of depression appearance, in contrast with adherence to western-diet alike patterns with elevated content in processed products and red meat [5]. Moreover, Godos et al. (2021) showed that attrition to similar, balanced dietary patterns was associated with enhanced sleep habits and sleep quality [6].

The effect of dietary habits has recently been incorporated in the attempt to collectively evaluate various lifestyle characteristics, via the construction of Lifestyle Indices (LI). Creation of LI is gaining more and more ground in recent literature and allows for the evaluation of the interconnected effect of multiple variables on phenotypic traits, such as obesity, cognitive abilities [7], development of other NCDs, such as cardiovascular disease [8] and overall mortality rates. Research studies including dietary habits in lifestyle indices are currently gaining more ground. Navarro et al., demonstrated the relationship between a maternal healthy lifestyle index, including calculation of the Healthy Eating Index (HEI), increased physical activity, pre-pregnancy BMI, smoking and alcohol drinking habits and the development of obesity in their offspring. Increased values of the index were negatively associated with obesity development during childhood [9]. Moreover, higher scores of a lifestyle index comprising of age, sex, smoking, drinking and exercise habits, sleep quality and BMI were associated with increased absolute mortality risk of older adults in Europe, United States, and the United Kingdom [10].

In this context, the present analyses represent the baseline results deriving from the iMPROVE study. The iMPROVE study, as a whole, attempts to evaluate gene-diet interactions in observed weight management, weight loss, body composition, and the lifestyle characteristics of a sample of overweight and obese Greek adults, adhering to one out of two hypocaloric dietary regimens of different macronutrient content, for a total duration of 6 months. The present article seeks to: (a) display the design, as well as the aims and objectives of the iMPROVE study and (b) evaluate the sample population's baseline dietary habits and potential relations with biochemical biomarkers. These analyses constitute the first step in assessing the effect of dietary habits on the participants' observed weight loss and further associate them with characteristics of genetic predisposition.

\section{Materials and Methods}

The Greek iMPROVE study constitutes a six-month randomized clinical trial, a nutritional intervention focusing on the investigation of gene-diet interactions on body weight regulation and lifestyle parameters. More specifically, the study aims at evaluating the role of target-genes in overweight and obese, Greek adults, under different dietary interventions. The study was approved by the Research Ethics Committee of Harokopio University of Athens (Protocol Number: 1800/13-06-2019) and was conducted at the premises of Harokopio University during the period 2020-2021. Recruitment took place in spring 2020 and handling and analysis of the data was, then, carried out during 2021. Moreover, the study was registered with the ClinicalTrials.gov database of the United States of America National Health Institute's (NIH) National Library of Medicine (ClinicalTrials.gov Identifier: NCT04699448). Due to the inclusion of human participants throughout its entirety, the trial was conducted adhering to the principles outlined in the Declaration of Helsinki. The study consisted of a sample of 202 overweight and obese, Greek adults, residing at the region of Attica at the time of recruitment. In this context, the present article summarizes the 
baseline characteristics of the study population and the associations observed between the participants' dietary habits and biomarkers of glycemic and lipidemic control at baseline.

\subsection{Nutritional Intervention Design and Study Population}

The overall aims of the iMPROVE study are summarized in the following: (a) To investigate the effect of adhering to two hypocaloric dietary regimens of different macronutrient content on the observed weight loss of overweight and obese adults; (b) to investigate gene-diet interactions concerning the weight management and various lifestyle characteristics of the study population; and (c) to investigate the utility of an original, online assessment tool as a way of long-distance evaluation of the volunteers' progress. In this spectrum, the objectives of the study were formed as follows: (a) To design a six-month, randomized clinical trial including overweight and obese adults, who were blindly recruited to following one out of two different hypocaloric dietary regimens and who were subject to two in-person follow-up meetings, conducted at three and six months (middle and end) after the beginning of the intervention; and (b) to create an original assessment tool to further monitor the monthly, self-reported progress of the volunteers throughout their participation in the intervention. The design of the study is shown in Figure 1.

\section{iMPROVE Study Flow Chart}

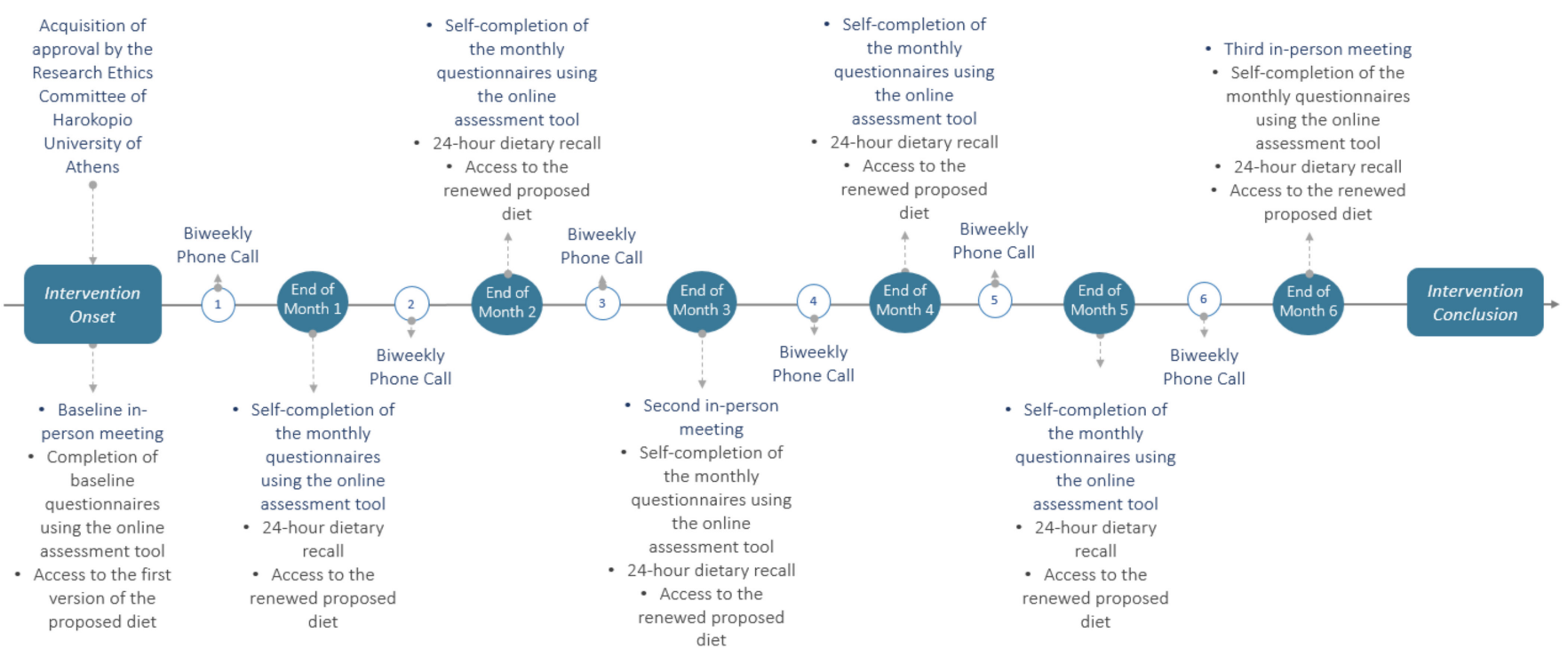

Figure 1. Flow chart of the iMPROVE Study. After completion of the baseline meeting, each participant was randomly allocated to one of the two proposed dietary intervention groups. Those referred either to a dietary regimen high in carbohydrates/low in fat, with $60 \%$ of energy intake deriving from carbohydrates, $18 \%$ deriving from protein, and $22 \%$ deriving from fat, or a dietary regimen high in protein, with $40 \%$ of the total energy intake coming from carbohydrates, $30 \%$ deriving from protein, and 30\% deriving from fat. Nutritional needs for each participant were calculated using the Mifflin equation and adjusted for their reported physical activity level (PAL). According to the guidelines of the National Institutes of Health (NIH) [11], optimal weight loss should take place aiming at a mean weight loss of 0.5 to $1 \mathrm{~kg}$ per week, which is translated to a $7500 \mathrm{kcal}$ reduction in the individual's weekly energy intake, or a $500 \mathrm{kcal}$ reduction on a daily basis. Therefore, daily individual nutritional needs for each participant were further reduced by $500 \mathrm{kcal}$. The team of Harokopio University of Athens created three categories of proposed hypocaloric diets with a mean energy content of $1500 \mathrm{kcal}, 1800$ $\mathrm{kcal}$, or $2000 \mathrm{kcal}$. Six different versions of the proposed diets, one for each intervention month, were created to allow for monthly renewal of the proposed diets, based on the participants' observed weight loss and dietary habits and/or tastes. The proposed diets concerned a 7-day pattern to be repeated for each month and mainly adhered to the Mediterranean pattern, including the daily consumption of 3 to 5 portions of fruit and vegetables and 1 to 2 portions of dairy products and the weekly consumption of 2 to 3 portions of grains, fish, and chicken, while limiting the consumption of red meat to 1 meal per week. 
Inclusion criteria for participation in the study consisted of: (a) age above 18 years old at the time of recruitment; (b) existence of a body mass index (BMI) of above $25 \mathrm{~kg} / \mathrm{m}^{2}$; (c) no reporting of extreme weight loss in the 3 to 6 months prior to the beginning of the intervention; and (d) maintenance of a stable level of physical activity prior to and throughout the duration of the intervention. Similarly, the exclusion criteria included: (a) For women, the existence of pregnancy or lactation, or intention of becoming pregnant in the 6 months during the intervention period; (b) the existence of diagnosed comorbidities related to increased body weight or disturbed dietary intake (i.e., diagnosed type 1 or 2 diabetes mellitus, cardiovascular disease, gastrointestinal disorders, mental illness or disorders related to dietary intake); (c) parallel intake of dietary supplements aiming at body weight loss; and (d) parallel participation in a different research study related to weight management and/or dietary intake.

Prospective participants received oral information on the proceedings and the aims of the trial and provided written consent prior to enrolment. All volunteers were asked to visit the premises of Harokopio University of Athens in order to attend the baseline assessment session and the two subsequent, in-person follow-up meetings at the middle and end of the intervention period. All meetings were conducted in the presence of a nutrition health-care professional (dietitian/nutritionist). All in-person sessions included clinical examination, anthropometric measurements, and collection of fasting blood samples. Participants were expected to use the originally created online assessment tool in order to complete questionnaires regarding anthropometric and lifestyle parameters at baseline and at the end of each month. Following successful completion of all monthly questionnaires, the participants were allowed access to the proposed dietary regimen at the beginning of each intervention month.

Furthermore, each participant was allocated a nutrition-expert contact who monitored their adherence to the patterns (Scheme 1) and progress by: (a) Conducting biweekly follow-up phone calls and monthly 24-h dietary recalls in order to discuss the potential concerns and provide advice, as to ensure maximum adherence to the proposed diet, (b) monitoring the monthly completion of all online questionnaires; (c) evaluating the participant's self-reported monthly weight; and (d) renewing and allowing access to the proposed diet at the online platform.

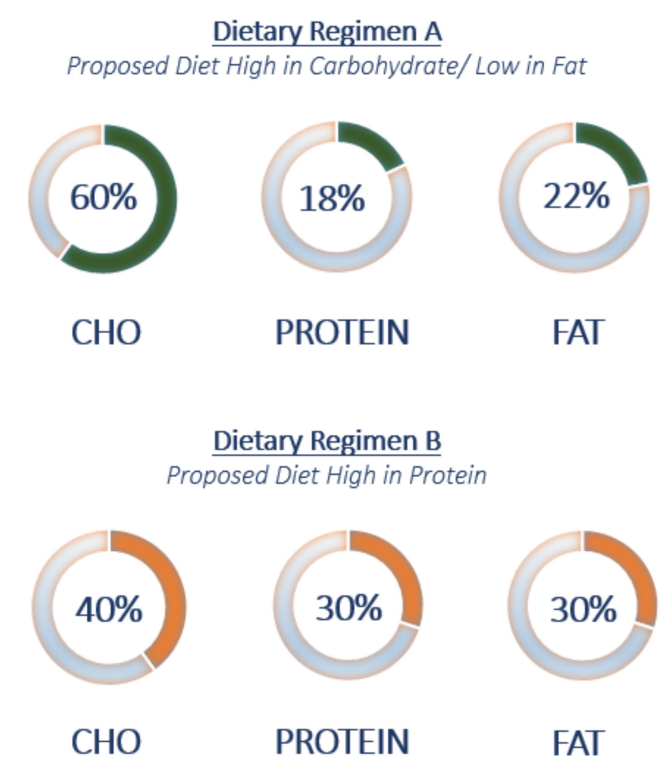

Scheme 1. Macronutrient distribution of the proposed diets.

\subsection{Online Assessment Tool}

For the purposes of the study, the team of Harokopio University of Athens created an online assessment tool including all the questionnaires that required completion from the 
volunteers, both at baseline and at a monthly level. The proposed diet was administered to the participant via access to the platform and was renewed monthly, once all questionnaires of the preceding month were checked by the nutrition expert. Access to the original, online assessment tool was granted with unique usernames and passwords for each volunteer. During the baseline session, each volunteer was taken on a virtual tour of the online assessment tool and was explicitly shown how to access and use it, by the nutrition expert.

At baseline, participants were required to complete questionnaires providing information on: (a) their medical history; (b) demographic characteristics; (c) feeling of satiety, by completing a 5 -scale short questionnaire; (d) adherence to the Mediterranean dietary pattern, by completing the questionnaire of the MedDiet Score [12]; (e) depression characteristics, by completing the DEPR-S-10 Questionnaire [13]; (f) characteristics of quality of life and health status, by completing the short version of the SF-12 Questionnaire [14]; (g) characteristics of quality of sleep, by completing the Athens Insomnia Scale Questionnaire [15]; (h) dietary habits, by completing a 69-item Food Frequency Questionnaire (FFQ) [16]; and (i) physical activity habits, by completing the short version of the IPAQ Questionnaire [17]. Completion of the SF-12, sleep and IPAQ Questionnaires at a monthly basis were also a prerequisite prior to the renewal of the proposed diet. Moreover, at the end of each month participants were further called to insert information on their anthropometric measurements (i.e., current weight, waist and hip circumference measurements), feeling of satiety and self-reported adherence to the proposed diet during the past month.

\subsection{Clinical Examination and Anthropometric Measurements}

During all three in-person meetings, clinical examination and anthropometric measurements were carried out by the trained dietitians or health-care or nutrition experts, using suitable equipment and standardized techniques. Clinical examination of the participants included: (a) evaluation of their physical status; and (b) blood pressure measurements, conducted after ensuring that the participant was at a calm state and at their bare, left upper arm, while sitting in an upright position with elevated feet and the arm supported at heart level.

The anthropometric data collected included: (a) Height measurements to the nearest $0.1 \mathrm{~cm}$, using a portable stadiometer, where the participant was barefoot, with relaxed shoulders and looking straight ahead; (b) weight measurements to the nearest $0.1 \mathrm{~kg}$, using the scales of the Tanita BC-418 Segmental Body Composition Analyzer, where the participant was barefoot and maintaining light clothing; (c) waist measurements (between the twelfth rib and the iliac crest), using a non-extensible soft tape; and (d) hip measurements, at the widest point of the hips, using a non-extensible soft tape. Participants were further shown and taught how to properly conduct the waist and hip circumference measurements, in order to monitor their progress and report it in the monthly anthropometric measurements' online questionnaire. Body composition analysis for individual participants was conducted via bioelectrical impedance analysis and more specifically, by using the Tanita BC-418 Segmental Body Composition Analyzer. The participants were refrained from food or water intake for at least two hours prior to the measurement conduct, be barefoot and maintain light clothing without any metal objects. Body composition data were acquired for each volunteer including body fat percentage, amount of body fat in kilos, distribution of body fat in the trunk and the limbs, body water percentage, and fat free mass. Body mass index (BMI) was calculated via dividing the weight $(\mathrm{kg})$ by the square height $\left(\right.$ in $\mathrm{m}^{2}$ ) for each participant and subjects were classified to the categories of: overweight $\left(25 \mathrm{~kg} / \mathrm{m}^{2} \leq \mathrm{BMI}<30 \mathrm{~kg} / \mathrm{m}^{2}\right)$, obese with class I obesity $\left(30 \mathrm{~kg} / \mathrm{m}^{2} \leq \mathrm{BMI}<35 \mathrm{~kg} / \mathrm{m}^{2}\right)$, obese with class II obesity $\left(35 \mathrm{~kg} / \mathrm{m}^{2} \leq \mathrm{BMI}<40 \mathrm{~kg} / \mathrm{m}^{2}\right)$, or obese with class III obesity $\left(B M I \geq 40 \mathrm{~kg} / \mathrm{m}^{2}\right)$.

\subsection{Biochemical Analyses}

Upon arrival to an in-person meeting and after following an 8-h fasting, a blood sample of $23 \mathrm{~mL}$ was collected from the antecubital vein of the participant by a trained health-care 
professional, following blood pressure measurements. Hematological biomarkers and biomarkers of biochemical profile were analyzed. All remaining samples were stored at $-80{ }^{\circ} \mathrm{C}$ for future analyses. Low-density cholesterol (LDL-C) was calculated using the Friedewald Equation.

\subsection{Genotyping Analyses}

The buffy coat samples isolated for each participant were used for DNA extraction, via use of the Invitrogen iPrep Purification Instrument and the Invitrogen iPrep PureLink gDNA Blood Kit [18]. Isolated samples were stored at $-20^{\circ} \mathrm{C}$ for a period of up to two months after extraction and prior to genotyping. Samples were stored at $-80{ }^{\circ} \mathrm{C}$, for a longer period and future analyses. All samples were sent for genome-wide sequencing using the Axiom Precision Medicine Diversity Research Array [19], which provided data for over 850,000 SNPs, deletions, and CNVs.

\subsection{Dietary Assessment}

Assessment of dietary intake at baseline took place by completing the validated 69item Food Frequency Questionnaire (FFQ) in the online assessment tool. Dietary assessment and evaluation of subsequent adherence to the proposed diet was conducted monthly via: (a) A 24-h dietary recall, carried out by the nutrition expert; and (b) completion of the 5 -scale self-reported adherence questionnaire, via use of the online assessment platform.

\subsection{Physical Activity Assessment}

Physical activity levels at baseline were assessed by completing the short version of the International Physical Activity Questionnaire (IPAQ) on the online platform. The same questionnaire was completed at the end of each intervention month.

\subsection{Statistical Analysis}

Data analyses were conducted using the Statistical Package for Social Sciences (SPSS), version 23 [20], as well as the R statistical package [21]. Dietary patterns were extracted by conducting principal component analysis (PCA) on 32 food groups deriving from the data of the FFQ. The Varimax orthogonal rotation was used and the KMO and Bartlett's test was implemented to evaluate data adequacy. Five dietary patterns were set to be extracted with Eigen values bigger than 1. Variable distribution was evaluated via the ShapiroWilk and Kolmogorov-Smirnov tests. Differences in mean/median values of variables within the two sexes were evaluated using the Mann-Whitney test. We further tested for potential associations between the extracted patterns and a variety of anthropometric and biochemical indices, via multivariate linear regressions. Non-normally distributed variables were log-transformed. We further examined the potential associations between the extracted patterns and several indices, by separating them into tertiles and testing for associations using the parametric ANOVA test and the non-parametric Kruskal-Wallis test, depending on the distribution of the examined variable. After analyzing the data for the entirety of the sample, a novel Lifestyle Index was constructed including variables found to be correlated with $\log$ BMI and body fat percentage, based on Pearson's chi-square test values. Further association tests (i.e., multivariate regressions) were conducted to assess the potential relationship between the Lifestyle Index and clinical and biochemical biomarkers. The level of statistical significance for all analyses was set at $\alpha=0.05$ and results were also interpreted for the adjusted cut-off value of $a=0.05 /$ number of patterns extracted (i.e., $\mathrm{a}=0.05 / 5=0.01)$.

\section{Results}

\subsection{Descriptive Statistics}

The entirety of the study population's anthropometric, clinical, dietary, and lifestyle characteristics are presented in Tables 1 and 2. Median \pm IQR is presented for all nonnormally distributed variables and mean \pm standard deviation (SD) is presented for the 
variables following the normal distribution. Out of the 235 volunteers expressing interest to participate in the study, data are shown for 202 eligible subjects who successfully attended the baseline meeting, completed the majority of the baseline questionnaires using the online tool, and were recruited in one of the two intervention arms. The sample size of the 202 individuals assures adequate power to detect statistical significance. Our baseline sample consisted of 142 women $(70.29 \%$ ) and 60 men (29.7\%), with a median age of 47 years old. The majority of participants were married $(60.9 \%)$, with more than half of our sample reporting having higher education $(61.9 \%)$ and less than $3 \%$ reporting having no acquired education at all. The vast majority of the participants were reported as nonsmokers (151 non-smokers vs. 50 smokers, out of 201 participants with available data). The estimated physical activity level showed that roughly half of the subjects were leading a moderately active way of life (104 out of the 199 participants with available data), with about $32 \%$ reporting a sedentary lifestyle. All 202 eligible volunteers were blindly recruited in the intervention groups, with $46.5 \%$ following the high-carbohydrate/low-fat diet and $53.5 \%$ adhering to the high-protein diet.

Table 1. Characteristics of the iMPROVE cohort by sex.

\begin{tabular}{|c|c|c|c|c|c|c|c|}
\hline \multirow[b]{2}{*}{$n$} & \multicolumn{2}{|c|}{ Smoking } & \multicolumn{3}{|c|}{ Physical Activity Categories } & \multicolumn{2}{|c|}{ Diet Group } \\
\hline & Smokers & Non-Smokers & Low & Moderate & Vigorous & $\begin{array}{c}\text { High } \\
\text { Carbohydrate/Low-Fat }\end{array}$ & High Protein \\
\hline Total & 50 & 151 & 64 & 104 & 31 & 94 & 108 \\
\hline Women & 38 & 103 & 43 & 76 & 30 & 74 & 68 \\
\hline Men & 12 & 48 & 21 & 28 & 11 & 20 & 40 \\
\hline
\end{tabular}

Table 2. Anthropometric, clinical, dietary characteristics and characteristics of depression, quality of sleep, and health status in the iMPROVE cohort, by sex.

\begin{tabular}{|c|c|c|c|c|c|c|c|c|c|c|}
\hline \multirow[t]{2}{*}{ Variable } & \multicolumn{3}{|c|}{ Total } & \multicolumn{3}{|c|}{ Women } & \multicolumn{3}{|c|}{ Men } & \multirow[t]{2}{*}{$p$-Value } \\
\hline & $\mathbf{n}$ & Median & IQR & $\mathbf{n}$ & Median & IQR & $\mathbf{n}$ & Median & IQR & \\
\hline Age & 202 & 47 & 15 & 142 & 47.50 & 14 & 60 & $45.78^{*}$ & $17^{*}$ & $p>0.05^{* *}$ \\
\hline SBP (mmHg) & 196 & 121.00 & 21 & 139 & 117.00 & 19 & 57 & 131.00 & 21 & $p<0.001^{* *}$ \\
\hline $\mathrm{DBP}(\mathrm{mmHg})$ & 196 & 80.84 * & $9.86^{*}$ & 139 & $78.68^{*}$ & $9.05 *$ & 57 & $86.09 *$ & $9.85 *$ & $p<0.001^{* *}$ \\
\hline Pulse Rate (Beats per minute) & 196 & 74.99 & 11.38 & 139 & 74.00 & 16 & 57 & 73.00 & 14 & $p>0.05^{* *}$ \\
\hline \multicolumn{11}{|c|}{ Anthropometric Characteristics } \\
\hline Weight $(\mathrm{kg})$ & 202 & 87.10 & 26 & 142 & 82.80 & 18 & 60 & 100.65 & 29 & $p<0.001^{* *}$ \\
\hline $\mathrm{BMI}\left(\mathrm{kg} / \mathrm{m}^{2}\right)$ & 202 & 31.34 & 6.9 & 142 & 31.34 & 6.9 & 60 & 31.33 & 7.1 & $p>0.05^{* *}$ \\
\hline Body fat (\%) & 202 & $37.95 *$ & $7.8^{*}$ & 142 & $41.50 *$ & 5.4 * & 60 & $29.55 *$ & $5.8^{*}$ & $p<0.001^{* *}$ \\
\hline Body fat $(\mathrm{kg})$ & 202 & 32.95 & 13.3 & 142 & 34.85 & 12.8 & 60 & 29.05 & 14.5 & $p<0.002^{* *}$ \\
\hline Fat free mass $(\mathrm{kg})$ & 202 & 52.05 & 18 & 142 & 48.50 & 7 & 60 & 71.20 & 15 & $p<0.001^{* *}$ \\
\hline Total body water (kg) & 202 & 38.05 & 13 & 142 & $36.35 *$ & $4.03 *$ & 60 & 52.10 & 11 & $p<0.001^{* *}$ \\
\hline Visceral fat & 202 & 10.00 & 6 & 142 & 9.74 & 3.16 & 60 & 14.50 & 5.69 & $p<0.001^{* *}$ \\
\hline Upper body fat (\%) & 201 & 36.60 & 10 & 141 & 38.50 & 8 & 60 & 32.10 & 8 & $p<0.001 * *$ \\
\hline Upper body fat $(\mathrm{kg})$ & 201 & 17.60 & 7 & 141 & 17.30 & 7 & 60 & 18.00 & 7 & $p>0.05^{* *}$ \\
\hline Upper body fat-free mass (kg) & 201 & 28.80 & 9 & 141 & $27.67 *$ & $2.75 *$ & 60 & 38.00 & 7 & $p<0.001^{* *}$ \\
\hline Waist circumference $(\mathrm{cm})$ & 185 & 99.00 & 17 & 130 & 96.50 & 15 & 55 & 105.00 & 17 & $p<0.001^{* *}$ \\
\hline Hip circumference $(\mathrm{cm})$ & 185 & 114.50 & 14 & 130 & 115.75 & 16 & 55 & 114.00 & 10 & $p>0.05^{* *}$ \\
\hline WHR & 185 & 0.85 & 0.12 & 130 & 0.83 & 0.09 & 55 & 0.92 & 0.09 & $p<0.001^{* *}$ \\
\hline \multicolumn{11}{|l|}{ Biochemical Biomarkers } \\
\hline Fasting glucose (mg/dL) & 193 & 92.00 & 10.50 & 135 & 92.00 & 10.00 & 58 & 95.00 & 16.25 & $p<0.001^{* *}$ \\
\hline Urea $(\mathrm{mg} / \mathrm{dL})$ & 193 & 28.00 & 9.00 & 135 & 27.00 & 9.00 & 58 & $30.12 *$ & $6.01 *$ & $p<0.001^{* *}$ \\
\hline Creatinine (mg/dL) & 193 & 0.68 & 0.21 & 135 & $0.62 *$ & $0.10 *$ & 58 & $0.85 *$ & $0.12 *$ & $p<0.001^{* * *}$ \\
\hline Uric acid(mg/dL) & 193 & 4.70 & 1.45 & 135 & 4.30 & 1.10 & 58 & $5.75 *$ & $1.00 *$ & $p<0.001^{* *}$ \\
\hline Total cholesterol (mg/dL) & 193 & $177.96^{*}$ & $33.57 *$ & 135 & 179.32 * & $31.98 *$ & 58 & 174.79 * & $37.13 *$ & $p>0.05^{* *}$ \\
\hline HDL cholesterol (mg/dL) & 193 & 49.00 & 16.50 & 135 & 52.00 & 17.00 & 58 & 42.00 & 14.50 & $p<0.001^{* *}$ \\
\hline
\end{tabular}


Table 2. Cont.

\begin{tabular}{|c|c|c|c|c|c|c|c|c|c|c|}
\hline \multirow[t]{2}{*}{ Variable } & \multicolumn{3}{|c|}{ Total } & \multicolumn{3}{|c|}{ Women } & \multicolumn{3}{|c|}{ Men } & \multirow[t]{2}{*}{$p$-Value } \\
\hline & $\mathbf{n}$ & Median & IQR & $\mathbf{n}$ & Median & IQR & $\mathbf{n}$ & Median & IQR & \\
\hline LDL cholesterol (mg/dL) & 193 & 105.20 & 38.70 & 135 & 105.00 & 38.40 & 58 & 108.00 & 42.05 & $p>0.05^{* *}$ \\
\hline Triglycerides (mg/dL) & 193 & 90.00 & 5.00 & 135 & 86.00 & 51.00 & 58 & 105.50 & 86.50 & $p<0.001^{* *}$ \\
\hline Total bilirubin (mg/dL) & 193 & 0.37 & 0.23 & 135 & 0.35 & 0.23 & 58 & 0.45 & 0.29 & $p<0.001 * *$ \\
\hline Direct bilirubin (mg/dL) & 193 & 0.16 & 0.08 & 135 & 0.15 & 0.09 & 58 & 0.17 & 0.08 & $p<0.001^{* *}$ \\
\hline Serum protein $(\mathrm{g} / \mathrm{dL})$ & 193 & 6.70 & 0.50 & 135 & 6.70 & 0.45 & 58 & 6.60 & 0.60 & $p>0.05^{* *}$ \\
\hline Serum albumin (g/dL) & 193 & 4.20 & 0.30 & 135 & 4.40 & 0.50 & 58 & 4.20 & 0.40 & $p<0.001^{* *}$ \\
\hline SGOT/AST (IU/L) & 193 & 16.00 & 6.00 & 135 & 15.00 & 5.00 & 58 & 18.00 & 5.25 & $p<0.001^{* *}$ \\
\hline SGPT/ALT (IU/L) & 192 & 15.00 & 11.75 & 134 & 13.00 & 9.00 & 58 & 22.00 & 16.25 & $p<0.001^{* *}$ \\
\hline \multicolumn{11}{|l|}{ Lifestyle Characteristics } \\
\hline AIS Score $* * *$ & 140 & 5.00 & 7.00 & 97 & 5.00 & 7.00 & 43 & 4.00 & 7.00 & $p>0.05^{* *}$ \\
\hline CESD-R-10 Scale & 201 & 6.00 & 5.00 & 141 & 6.00 & 4.00 & 60 & 5.00 & 5.75 & $p<0.001^{* *}$ \\
\hline SF PCS 12 Score & 145 & 51.98 & 12 & 99 & 50.37 & 11 & 46 & 53.82 & 8 & $p<0.001^{* *}$ \\
\hline SF MCS 12 Score & 145 & 49.37 & 15 & 99 & 49.44 & 16 & 46 & $46.62 *$ & 8.36 & $p>0.001 * *$ \\
\hline
\end{tabular}

* The selected variables follow the normal distribution and are presenting as mean \pm standard deviation. ${ }^{* *}$ Statistically significant differences between the sexes were assessed via calculation of the Mann-Whitney test. ${ }^{* * *}$ The Athens Insomnia Scale Score was calculated only for participants reporting the referred characteristics $\geq 3$ times/week for the past month. SBP: systolic blood pressure; DBP: diastolic blood pressure; BMI: body mass index; WHR: waist-to-hip ratio; HDL: high-density lipoprotein; LDL: low-density lipoprotein; SGOT / AST: glutamic oxaloacetic transaminase/aspartate transaminase; SGPT/ALT: glutamate pyruvate transaminase blood/alanine transaminase; AIS: Athens Insomnia Scale; CESD-R-10: Center for Epidemiologic Studies Depression Scale Revised-10; SF PCS 12: Short Form (Health Survey) Physical Component Score 12; SF MCS 12: Short Form (Health Survey) Mental Component Score 12.

Overweight participants constituted $38.6 \%$ of our overall sample, with the remaining $61.4 \%$ spreading across the three different obesity categories $(35.1 \%, 14.9 \%$, and $11.4 \%$ of the participants classified as Class I, II, or III obese, respectively). Median BMI was calculated at $31.34 \mathrm{~kg} / \mathrm{m}^{2}$ and did not differ between men and women, whereas body composition data displayed statistically significant differences between the two sexes, with men reporting higher levels of fat-free mass $(71.20 \mathrm{~kg}$ vs. $48.50 \mathrm{~kg}, p<0.001)$ and total body water $(p<0.001)$ and women presenting increased body fat values $(41.40 \%$ vs. $29.55 \%$, $p<0.001)$. Although men were found to have increased waist-to-hip ratio (WHR) ( $0.92 \mathrm{vs.}$ $0.83, p<0.001)$ waist circumference in comparison to women $(105 \mathrm{~cm}$ vs. $96.5 \mathrm{~cm}, p<0.001)$, hip circumference did not present significant differences. Similar differences were further observed in the clinical characteristics, with men reporting higher levels of blood pressure, fasting glucose $(95 \mathrm{mg} / \mathrm{dL}$ vs. $92 \mathrm{mg} / \mathrm{dL}, p<0.001)$, serum urea $(30.12 \mathrm{mg} / \mathrm{dL}$ vs. $27.00 \mathrm{mg} / \mathrm{dL}, p<0.001)$, creatinine $(0.12 \mathrm{mg} / \mathrm{dL}$ vs. $0.10 \mathrm{mg} / \mathrm{dL}, p<0.001)$, uric acid levels $(5,75 \mathrm{mg} / \mathrm{dL}$ vs. $4.30 \mathrm{mg} / \mathrm{dL}, p<0.001)$, total triglycerides $(105.5 \mathrm{mg} / \mathrm{dL}$ vs. $86 \mathrm{mg} / \mathrm{dL}$, $p<0.001)$, serum bilirubin $(0.45 \mathrm{mg} / \mathrm{dL}$ vs. $0.35 \mathrm{mg} / \mathrm{dL}, p<0.001)$, SGOT (18 IU/L vs. $15 \mathrm{IU} / \mathrm{L}, p<0.001)$, and SGPT levels (22.00 IU/L vs. $13 \mathrm{IU} / \mathrm{L}, p<0.001)$. Women presented higher levels of HDL cholesterol $(52.00 \mathrm{mg} / \mathrm{dL}$ vs. $42.00 \mathrm{mg} / \mathrm{dL}, p<0.001)$ and serum albumin levels ( $4.40 \mathrm{~g} / \mathrm{dL}$ vs. $4.20 \mathrm{~g} / \mathrm{dL}, p<0.001)$.

\subsection{Lifestyle Characteristics}

The 8-item Athens Insomnia Scale (AIS) score on evaluation of sleep qualities was calculated for participants who reported the selected outcomes more than three times per week in the month leading to the beginning of the intervention. The AIS score presented a median of 5 out of the scale maximum scoring of 24 and did not display statistically significant differences between the sexes. Overall, participants did not express significant irregularities neither in sleep quality, including sleep induction, total sleep duration, and awakenings at night and expressed delayed sleep induction, nor in effects of sleep on aspects of the next day (i.e., well-being, overall functioning, and sleepiness).

Contrary to the AIS score, the CESD-R-10 scale score on depression characteristics showed that women displayed higher median values (scoring of 6 vs. $5, p<0.001$ ). The majority of the participants did not display depression characteristics, such as feelings of fear and helplessness, with the overall sample presented a mean CESD-R-10 score of 6, with the scale maximum scoring calculated at 18 . Moreover, the physical component of 
the SF-12 score on self-reported quality of life underlined increased levels in men than in women ( 53,82 vs. 50, 37, $p<0.001)$, whereas the mental component did not show important dissimilarities. No statistically significant differences were found when the participants were classified into the four different BMI groups (Figures 2 and 3).

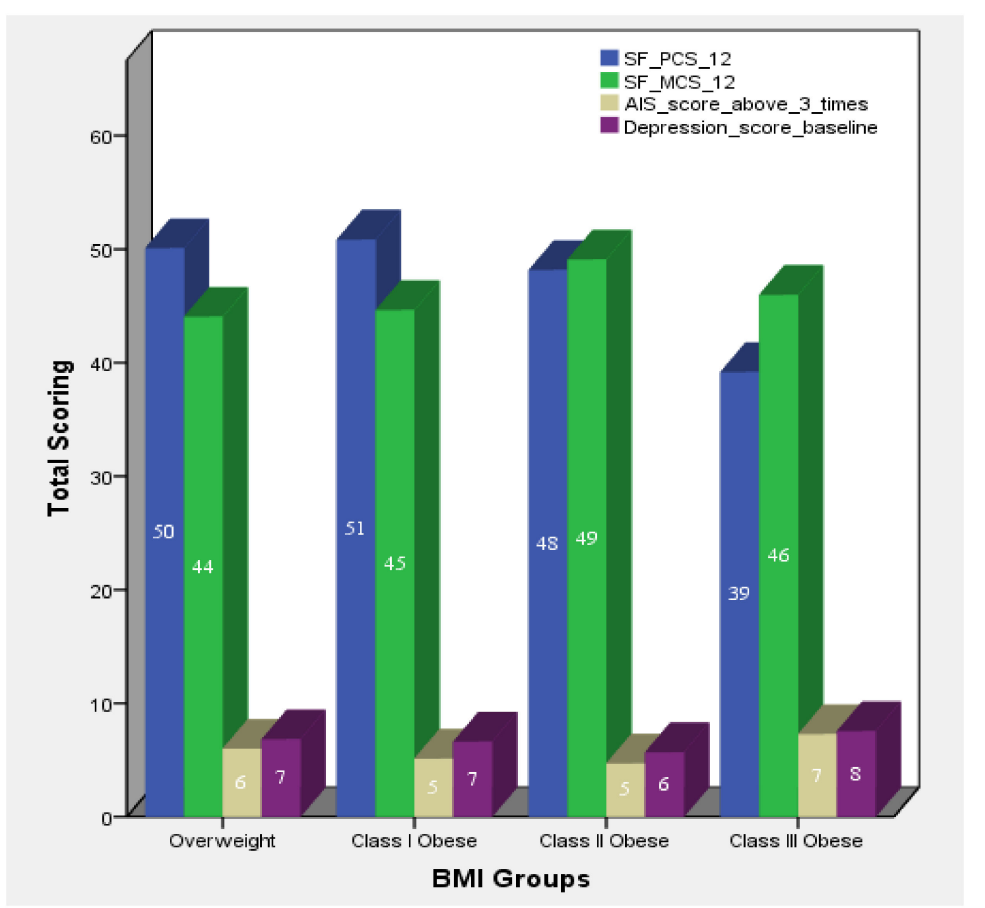

Figure 2. Baseline scoring of the four lifestyle questionnaires, based on BMI categories.

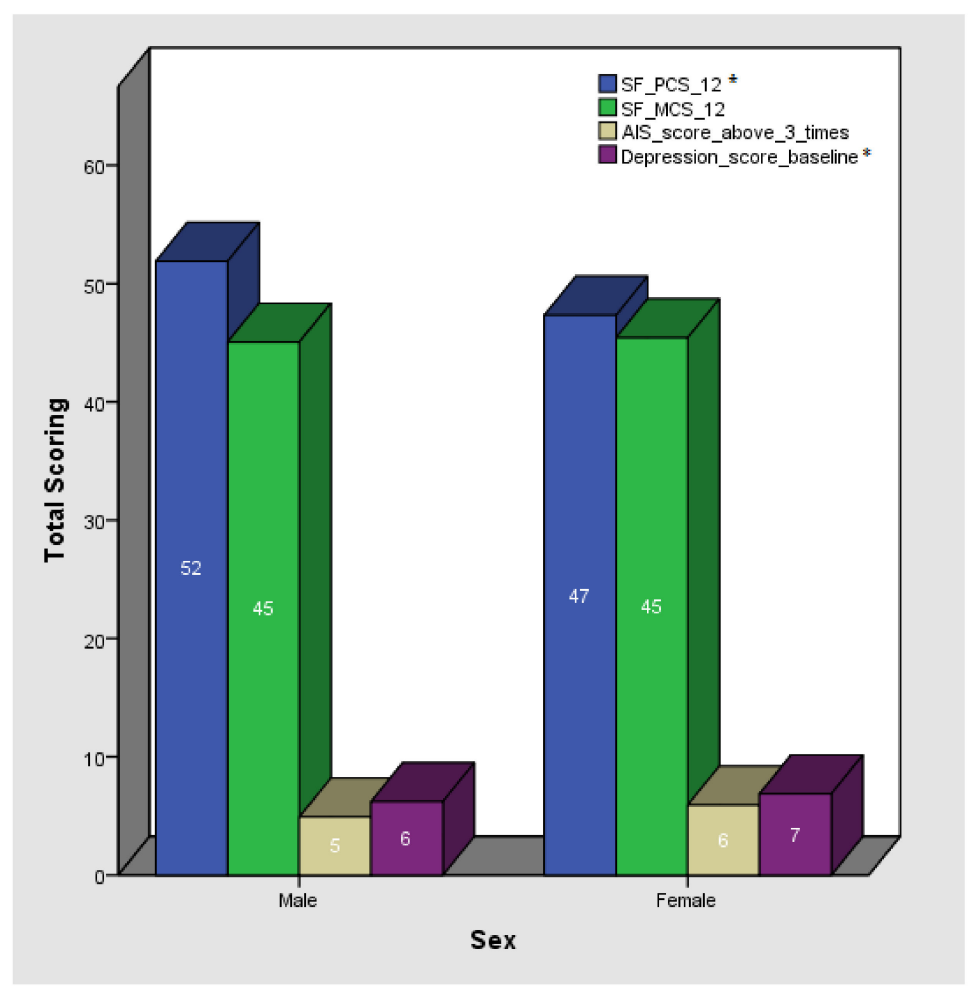

Figure 3. Baseline scoring of the four lifestyle questionnaires, based on sex ( ${ }^{*}$ The presented variables were statistically significantly different between the sexes.). 
As shown in Table 3. we further investigated the potential effect of the aforementioned lifestyle aspects on $\log$ BMI and \%body fat baseline levels. After adjusting for confounding factors including age, sex, smoking habits, physical activity level and education years, Only the physical component of the SF-12 questionnaire (SF PCS 12 Score) was found to be associated with the characteristics of interest, displaying a negative effect on both logBMI and \%body fat values $(\beta=-0.003, p<0.001$ and $\beta=-0.218$, respectively).

Table 3. Multivariate linear regression analyses on the relation between lifestyle characteristics and $\mathrm{BMI}$ and body fat baseline values.

\begin{tabular}{lccc}
\hline \multicolumn{1}{c}{ Variable } & \multicolumn{3}{c}{ Model 1 $^{*}$} \\
\cline { 2 - 4 } & $\boldsymbol{B}$ & $\boldsymbol{S}$ & $\boldsymbol{p}$-Value \\
\hline logBMI & & & \\
Athens Insomnia Scale Score & 0.001 & 0.001 & 0.612 \\
CESD-R-10 Scale & 0.002 & 0.001 & 0.189 \\
SF PCS 12 Score & -0.003 & 0.001 & $<0.001$ \\
SF MCS 12 Score & 0.001 & 0.001 & 0.217 \\
Body fat (\%) & & & \\
Athens Insomnia Scale Score & 0.188 & 0.128 & 0.143 \\
CESD-R-10 Scale & 0.175 & 0.100 & 0.083 \\
SF PCS 12 Score & -0.218 & 0.057 & $<0.001$ \\
SF MCS 12 Score & 0.049 & 0.054 & 0.371 \\
\hline
\end{tabular}

* Model 1: Adjusting for age, sex, smoking, physical activity level and education years.

\subsection{Dietary Patterns}

PCA on the available data of the 202 participants' FFQs resulted in the identification of five dietary patterns accounting for $40.34 \%$ of the sample's total variance. The KMO and Bartlett's Test $(p<0.001)$ presented a Kaiser-Meyer-Olkin Measure of 0.726, indicating sufficient data adequacy. All factor loadings for each component were above or approaching a value of 0.3 . As shown in Table 4, the 32 food groups formed based on the 69-item questions, included in the analysis reflected the variety of foodstuffs consumed by the sample population, including both widely consumed food categories such as meat and cereals, as well as traditional Greek recipes (i.e., pastitsio, spinach rice, and homemade pies). Alcohol and beer reported servings were included in the analysis, due to the sample's low median values ( 2 and $16 \mathrm{~mL} / \mathrm{d}$, respectively) and the lack of heavy drinkers. 
Table 4. Mean consumption and PCA factor loadings of the 32 FFQ-derived food groups.

\begin{tabular}{|c|c|c|c|c|c|c|c|}
\hline & \multirow[b]{2}{*}{$\begin{array}{l}\text { Mean Consumption } \\
\text { (Median. IQR) }\end{array}$} & \multirow[b]{2}{*}{ Food Group } & \multicolumn{5}{|c|}{ Components } \\
\hline & & & 1 & 2 & 3 & 4 & 5 \\
\hline Croissant (g/d) & $5.2(11.56)$ & \multirow{4}{*}{ Sweets } & \multirow{4}{*}{0.705} & & & & \\
\hline Chocolate (g/d) & $12.85(8.85)$ & & & & & & \\
\hline Tarts (g/d) & $10.00(10.00)$ & & & & & & \\
\hline Ice cream $(\mathrm{g} / \mathrm{d})$ & $7.66(24.64)$ & & & & & & \\
\hline Mayonnaise (g/d) & $1.11(2.02) *$ & Mayonnaise & 0.664 & & & & \\
\hline White bread $(\mathrm{g} / \mathrm{d})$ & $19.28(17.28)$ & \multirow{5}{*}{ Refined Cereals } & \multirow{5}{*}{0.643} & & & & \\
\hline Cereals (g/d) & $4.28(4.28)$ & & & & & & \\
\hline White rice $(\mathrm{g} / \mathrm{d})$ & $10.53(23.32)$ & & & & & & \\
\hline Barley $(\mathrm{g} / \mathrm{d})$ & $9.33(30.00)$ & & & & & & \\
\hline Burger bread (g/d) & $3.00(10.44) *$ & & & & & & \\
\hline Chips (g/d) & $4.66(4.66)$ & \multirow{2}{*}{ Salty Snacks } & \multirow{2}{*}{0.628} & & & & \\
\hline Crackers (g/d) & $1.33(4.28)$ & & & & & & \\
\hline Honey $(\mathrm{g} / \mathrm{d})$ & $1.07(4.66)$ & \multirow{3}{*}{ Sugary Snacks } & \multirow{3}{*}{0.596} & & & & \\
\hline Soft drinks (mL/d) & $28.69(72.42) *$ & & & & & & \\
\hline Fruit compost (g/d) & $7.5896 .66)^{*}$ & & & & & & \\
\hline Tray Sweets (g/d) & $10.00(10.00)$ & Tray Sweets & 0.584 & & & & \\
\hline Pastitsio (g/d) & $10.00(10.00)$ & Pastitsio & 0.493 & & & & \\
\hline $\begin{array}{l}\text { Potatoes (boiled. } \\
\text { cooked. not } \\
\text { fried) }(\mathrm{g} / \mathrm{d})\end{array}$ & $11.53(25.53)$ & $\begin{array}{l}\text { Potatoes (boiled, } \\
\text { cooked, not fried) }\end{array}$ & 0.469 & & & & \\
\hline Chicken (g/d) & $32.14(0.00)$ & Chicken & 0.388 & & & & \\
\hline Seed oil $(\mathrm{g} / \mathrm{d})$ & $3.23(8.09) *$ & \multirow{3}{*}{$\begin{array}{c}\text { Seed oil, } \\
\text { margarine, butter }\end{array}$} & \multirow{3}{*}{0.374} & & & & \\
\hline Margarine $(\mathrm{g} / \mathrm{d})$ & $1.03(2.46)^{*}$ & & & & & & \\
\hline Butter (g/d) & $0.50(1.00)$ & & & & & & \\
\hline $\begin{array}{l}\text { Light mayonnaise } \\
\text { (g/d) }\end{array}$ & $0.71(1.84) *$ & \multirow{3}{*}{ Light Products } & \multirow{3}{*}{0.367} & & & & \\
\hline $\begin{array}{l}\text { Light cold } \\
\text { cuts }(\mathrm{g} / \mathrm{d})\end{array}$ & $2.00(6.42)$ & & & & & & \\
\hline $\begin{array}{l}\text { Light soft } \\
\text { drinks }(\mathrm{g} / \mathrm{d})\end{array}$ & $22.00(70.71)$ & & & & & & \\
\hline Sausage (g/d) & $1.08(1.45)$ & & & & & -0.342 & \\
\hline Tomatoes (g/d) & $64.28(42.85)$ & \multirow{4}{*}{ Vegetables } & & \multirow{4}{*}{0.640} & & & \\
\hline Lettuce (g/d) & $34.28(34.28)$ & & & & & & \\
\hline Broccoli $(\mathrm{g} / \mathrm{d})$ & $21.42(14.76)$ & & & & & & \\
\hline Spinach (g/d) & $6.00(13.28)$ & & & & & & \\
\hline $\begin{array}{l}\text { Full fat } \\
\text { milk (mL/d) }\end{array}$ & $43.46(71.26)$ & \multirow{3}{*}{ Dairy } & & \multirow{3}{*}{0.568} & & & \\
\hline Low fat milk & $51.42(154.28)$ & & & & & & \\
\hline White cheese $(\mathrm{g} / \mathrm{d})$ & $6.42(17.28)$ & & & & & & \\
\hline Eggs (g/d) & $10.71(7.38)$ & Eggs & & 0.562 & & & \\
\hline Oranges $(\mathrm{g} / \mathrm{d})$ & $36.42(97.95)$ & \multirow{5}{*}{ Fruits } & & \multirow{5}{*}{0.525} & & & \\
\hline Apples (g/d) & $30.00(80.66)$ & & & & & & \\
\hline Bananas (g/d) & $21.42(57.61)$ & & & & & & \\
\hline Winter fruit $(\mathrm{g} / \mathrm{d})$ & $32.14(86.42)$ & & & & & & \\
\hline Summer fruit & $32.14(64.28)$ & & & & & & \\
\hline
\end{tabular}


Table 4. Cont.

\begin{tabular}{|c|c|c|c|c|c|c|c|}
\hline & \multirow[b]{2}{*}{$\begin{array}{l}\text { Mean Consumption } \\
\text { (Median. IQR) }\end{array}$} & \multirow[b]{2}{*}{ Food Group } & \multicolumn{5}{|c|}{ Components } \\
\hline & & & 1 & 2 & 3 & 4 & 5 \\
\hline Whole bread $(\mathrm{g} / \mathrm{d})$ & $19.28(17.28)$ & \multirow{3}{*}{$\begin{array}{l}\text { Non-refined } \\
\text { cereals }\end{array}$} & & \multirow{3}{*}{0.443} & & & \\
\hline Brown rice $(\mathrm{g} / \mathrm{d})$ & $6.72(14.73)^{*}$ & & & & & & \\
\hline Whole pasta (g/d) & $8.54(9.33)$ & & & & & & \\
\hline Large fish (g/d) & $10.00(22.14)$ & Large fish & & 0.432 & & & \\
\hline Olive oil (g/d) & $45.00(45.00)$ & Olive oil & & 0.345 & & & \\
\hline Dried fruit $(\mathrm{g} / \mathrm{d})$ & $3.35(6.88) *$ & Dried fruit & & 0.330 & & & \\
\hline Coffee $(\mathrm{mL} / \mathrm{d})$ & $240.00(240.00)$ & \multirow{2}{*}{$\begin{array}{l}\text { Caffeinated } \\
\text { Beverages }\end{array}$} & & & & \multirow{2}{*}{-0.504} & \\
\hline Tea (mL/d) & $16.00(51.42)$ & & & & & & \\
\hline Seafood $(\mathrm{g} / \mathrm{d})$ & $10.00(10.00)$ & Seafood & & & 0.685 & & \\
\hline French Fries $(g / d)$ & $4.83(15.53)$ & French Fries & & & 0.648 & & \\
\hline $\begin{array}{l}\text { Homemade } \\
\text { pies }(\mathrm{g} / \mathrm{d})\end{array}$ & $10.00(0.00)$ & \multirow[t]{2}{*}{ Pies } & & & \multirow[t]{2}{*}{0.510} & & \\
\hline Other pies $(\mathrm{g} / \mathrm{d})$ & $10.00(10.00)$ & & & & & & \\
\hline Beef $(g / d)$ & $10.00(22.14)$ & \multirow{4}{*}{ Red Meat } & & & \multirow{4}{*}{0.499} & & \\
\hline Minced beef & $25.71(17.71)$ & & & & & & \\
\hline Pork $(\mathrm{g} / \mathrm{d})$ & $10.00(22.14)$ & & & & & & \\
\hline $\operatorname{Lamb}(\mathrm{g} / \mathrm{d})$ & $5.83(13.84)$ & & & & & & \\
\hline Alcohol (mL/d) & $2.00(6.42)$ & \multirow{2}{*}{ Alcohol and Beer } & & & \multirow{2}{*}{0.398} & & \\
\hline $\operatorname{Beer}(\mathrm{mL} / \mathrm{d})$ & $16.00(51.42)$ & & & & & & \\
\hline Legumes $(\mathrm{g} / \mathrm{d})$ & $64.28(44.28)$ & Legumes & & & & 0.698 & \\
\hline $\begin{array}{l}\text { Spinach and } \\
\text { Rice }(\mathrm{g} / \mathrm{d})\end{array}$ & $16.66(53.57)$ & \multirow{2}{*}{$\begin{array}{l}\text { Traditional, Greek } \\
\text { recipes }\end{array}$} & & & & \multirow{2}{*}{0.695} & \\
\hline Green Peas $(\mathrm{g} / \mathrm{d})$ & $42.85(29.52)$ & & & & & & \\
\hline Olives & $1.00(3.21)$ & Olives & & & & & 0.645 \\
\hline Small fish (g/d) & $10.00(32.14)$ & Small fish & & & & & 0.584 \\
\hline Nuts $(g / d)$ & $3.33(28.81)$ & Nuts & & & & & 0.343 \\
\hline Fruit Juice (g/d) & $16.00(51.42)$ & Fruit Juice & & & & & 0.311 \\
\hline $\begin{array}{l}\text { Total Variance } \\
\text { Explained (\%) }\end{array}$ & & & $14.74 \%$ & $9.87 \%$ & $6.26 \%$ & $4.96 \%$ & $4.49 \%$ \\
\hline
\end{tabular}

The dietary patterns provided are summarized in the following (Table 5): (a) The "Mixed" pattern (total variance explained: $14.74 \%$ ) which reported the consumption of a variety of food groups including both light products and processed products high in fat and sugars (i.e., sweets, mayonnaise, refined cereals, salty snacks, sugary snacks, tray sweets, the Greek pastitsio, potatoes, chicken, seed oil, margarine, butter, light products, and sausage); (b) the "Mediterranean-proxy" (or Med-proxy) pattern (total variance explained: $9.87 \%$ ), including the consumption of food groups usually found in the Mediterranean diet, such a vegetables, dairy, eggs, fruits, non-refined cereals, large fish, olive oil, dried fruit, and caffeinated drinks, such as coffee and tea; (c) the "Eating out" pattern (total variance explained: $6.26 \%$ ), consisting of food group combinations frequently consumed outside the household, i.e., seafood, French fries, pies, red meat and alcohol; (d) the "Traditional, vegetarian-alike" pattern (total variance explained: 4.96\%), reporting consumption of legumes and traditional Greek recipes (i.e., spinach rice and cooked green peas); and (e) "High in unsaturated fats and fruit juice consumption" pattern (total variance explained: $4.49 \%$ ), consisting of olives, small fish, nuts and fruit juice, with the first, high in unsaturated fats and fruit juice consumption, groups presenting the greatest factor loadings. 
Table 5. Multivariate linear regressions between the extracted dietary patterns and indices of anthropometric and biochemical characteristics.

\begin{tabular}{|c|c|c|c|c|c|c|c|c|c|}
\hline & \multicolumn{3}{|c|}{ Model 1} & \multicolumn{3}{|c|}{ Model 2} & \multicolumn{3}{|c|}{ Model 3} \\
\hline & $\beta$ & $S E$ & $p$-Value & $\beta$ & $S E$ & $p$-Value & $\beta$ & $S E$ & $p$-Value \\
\hline LogBMI & & & & & & & & & \\
\hline Mixed Pattern & 0.019 & 0.005 & $<0.001$ & 0.017 & 0.005 & 0.001 & 0.015 & 0.005 & 0.009 \\
\hline Med-proxy Pattern & -0.002 & 0.005 & 0.758 & $<0.001$ & 0.005 & 0.937 & -0.001 & 0.006 & 0.867 \\
\hline Eating-out Pattern & 0.004 & 0.005 & 0.366 & 0.004 & 0.005 & 0.432 & 0.001 & 0.005 & 0.780 \\
\hline $\begin{array}{c}\text { Traditional, vegetarian-alike } \\
\text { Pattern }\end{array}$ & -0.005 & 0.005 & 0.272 & -0.008 & 0.005 & 0.132 & -0.008 & 0.005 & 0.132 \\
\hline $\begin{array}{l}\text { High in unsaturated fats and } \\
\text { fruit juice consumption Pattern } \\
\text { Body fat } \%\end{array}$ & -0.005 & 0.005 & 0.338 & -0.006 & 0.005 & 0.269 & -0.006 & 0.005 & 0.281 \\
\hline Mixed Pattern & 1.179 & 0.392 & 0.003 & -0.149 & 0.230 & 0.516 & -0.195 & 0.259 & 0.451 \\
\hline Med-proxy Pattern & -0.010 & 0.423 & 0.982 & 0.261 & 0.234 & 0.266 & 0.351 & 0.255 & 0.171 \\
\hline Eating-out Pattern & 0.316 & 0.399 & 0.430 & 0.005 & 0.217 & 0.982 & -0.045 & 0.232 & 0.848 \\
\hline $\begin{array}{c}\text { Traditional, vegetarian-alike } \\
\text { Pattern }\end{array}$ & -0.770 & 0.387 & 0.048 & -0.476 & 0.221 & 0.032 & -0.402 & 0.236 & 0.090 \\
\hline $\begin{array}{l}\text { High in unsaturated fats and } \\
\text { fruit juice consumption Pattern } \\
\text { LogVisceral Fat }\end{array}$ & -0.335 & 0.400 & 0.404 & 0.054 & 0.220 & 0.808 & 0.167 & 0.236 & 0.480 \\
\hline Mixed Pattern & 0.032 & 0.009 & 0.001 & -0.002 & 0.004 & 0.633 & $<0.001$ & 0.004 & 0.980 \\
\hline Med-proxy Pattern & -0.002 & 0.010 & 0.808 & 0.002 & 0.004 & 0.629 & 0.004 & 0.004 & 0.302 \\
\hline Eating-out Pattern & 0.011 & 0.010 & 0.266 & 0.002 & 0.004 & 0.548 & 0.002 & 0.004 & 0.642 \\
\hline $\begin{array}{c}\text { Traditional, vegetarian-alike } \\
\text { Pattern }\end{array}$ & -0.018 & 0.009 & 0.058 & -0.008 & 0.004 & 0.032 & -0.007 & 0.004 & 0.088 \\
\hline $\begin{array}{l}\text { High in unsaturated fats and } \\
\text { fruit juice consumption Pattern } \\
\text { logCreatinine }(\mathrm{mg} / \mathrm{dL})\end{array}$ & -0.007 & 0.010 & 0.450 & 0.002 & 0.004 & 0.522 & 0.006 & 0.004 & 0.139 \\
\hline Mixed Pattern & 0.008 & 0.005 & 0.136 & 0.008 & 0.006 & 0.143 & 0.012 & 0.006 & 0.048 \\
\hline Med-proxy Pattern & -0.008 & 0.006 & 0.150 & -0.010 & 0.006 & 0.066 & -0.013 & 0.006 & 0.029 \\
\hline Eating-out Pattern & -0.001 & 0.005 & 0.897 & 0.001 & 0.005 & 0.848 & 0.001 & 0.006 & 0.875 \\
\hline $\begin{array}{c}\text { Traditional, vegetarian-alike } \\
\text { Pattern }\end{array}$ & -0.003 & 0.005 & 0.549 & -0.008 & 0.005 & 0.155 & -0.008 & 0.006 & 0.149 \\
\hline $\begin{array}{l}\text { High in unsaturated fats and } \\
\text { fruit juice consumption Pattern } \\
\text { logHDL Cholesterol (mg/dL) }\end{array}$ & 0.002 & 0.005 & 0.648 & 0.001 & 0.005 & 0.802 & 0.001 & 0.006 & 0.876 \\
\hline Mixed Pattern & -0.020 & 0.007 & 0.006 & -0.013 & 0.007 & 0.079 & -0.016 & 0.009 & 0.057 \\
\hline Med-proxy Pattern & -0.005 & 0.008 & 0.528 & -0.009 & 0.008 & 0.257 & -0.010 & 0.008 & 0.245 \\
\hline Eating-out Pattern & 0.009 & 0.007 & 0.229 & 0.011 & 0.007 & 0.135 & 0.013 & 0.008 & 0.082 \\
\hline $\begin{array}{c}\text { Traditional, vegetarian-alike } \\
\text { Pattern }\end{array}$ & 0.013 & 0.007 & 0.054 & 0.017 & 0.007 & 0.017 & 0.016 & 0.008 & 0.039 \\
\hline $\begin{array}{l}\text { High in unsaturated fats and } \\
\text { fruit juice consumption Pattern } \\
\text { logTriglycerides }(\mathrm{mg} / \mathrm{dL})\end{array}$ & 0.005 & 0.007 & 0.483 & 0.006 & 0.007 & 0.445 & 0.003 & 0.008 & 0.688 \\
\hline Mixed Pattern & 0.038 & 0.014 & 0.007 & 0.021 & 0.015 & 0.155 & 0.033 & 0.016 & 0.048 \\
\hline Med-proxy Pattern & -0.008 & 0.015 & 0.579 & -0.003 & 0.015 & 0.850 & -0.002 & 0.016 & 0.908 \\
\hline Eating-out Pattern & $<0.001$ & 0.014 & 0.998 & -0.003 & 0.014 & 0.816 & -0.007 & 0.015 & 0.622 \\
\hline $\begin{array}{c}\text { Traditional, vegetarian-alike } \\
\text { Pattern }\end{array}$ & 0.009 & 0.014 & 0.509 & 0.006 & 0.014 & 0.662 & 0.015 & 0.015 & 0.316 \\
\hline $\begin{array}{l}\text { High in unsaturated fats and } \\
\text { fruit juice consumption Pattern } \\
\text { logTotal Bilirubin(mg/dL) }\end{array}$ & 0.002 & 0.014 & 0.875 & $<0.001$ & 0.015 & 0.976 & -0.004 & 0.016 & 0.788 \\
\hline Mixed Pattern & -0.002 & 0.015 & 0.913 & 0.001 & 0.017 & 0.971 & 0.013 & 0.018 & 0.472 \\
\hline Med-proxy Pattern & -0.036 & 0.016 & 0.025 & -0.043 & 0.017 & 0.010 & -0.042 & 0.018 & 0.019 \\
\hline Eating-out Pattern & -0.005 & 0.015 & 0.735 & -0.001 & 0.015 & 0.943 & -0.005 & 0.016 & 0.772 \\
\hline $\begin{array}{c}\text { Traditional, vegetarian-alike } \\
\text { Pattern }\end{array}$ & 0.032 & 0.015 & 0.031 & 0.030 & 0.016 & 0.059 & 0.033 & 0.016 & 0.047 \\
\hline
\end{tabular}


Table 5. Cont.

\begin{tabular}{|c|c|c|c|c|c|c|c|c|c|}
\hline & \multicolumn{3}{|c|}{ Model 1} & \multicolumn{3}{|c|}{ Model 2} & \multicolumn{3}{|c|}{ Model 3} \\
\hline & $\beta$ & $S E$ & $p$-Value & $\beta$ & $S E$ & $p$-Value & $\beta$ & $S E$ & $p$-Value \\
\hline $\begin{array}{l}\text { High in unsaturated fats and } \\
\text { fruit juice consumption Pattern } \\
\text { logSerum protein }(\mathrm{g} / \mathrm{dL})\end{array}$ & 0.018 & 0.016 & 0.255 & 0.015 & 0.016 & 0.357 & 0.016 & 0.017 & 0.356 \\
\hline Mixed Pattern & 0.004 & 0.002 & 0.036 & 0.003 & 0.002 & 0.187 & 0.005 & 0.002 & 0.029 \\
\hline Med-proxy Pattern & -0.001 & 0.002 & 0.575 & -0.001 & 0.002 & 0.720 & $<0.000$ & 0.002 & 0.829 \\
\hline Eating-out Pattern & -0.001 & 0.002 & 0.603 & -0.001 & 0.002 & 0.599 & -0.002 & 0.002 & 0.273 \\
\hline $\begin{array}{c}\text { Traditional, vegetarian-alike } \\
\text { Pattern }\end{array}$ & 0.002 & 0.002 & 0.164 & 0.002 & 0.002 & 0.217 & 0.003 & 0.002 & 0.136 \\
\hline $\begin{array}{l}\text { High in unsaturated fats and } \\
\text { fruit juice consumption Pattern } \\
\text { LogSGOT/AST(IU /L) }\end{array}$ & 0.001 & 0.002 & 0.525 & 0.001 & 0.002 & 0.530 & $<0.001$ & 0.002 & 0.794 \\
\hline Mixed Pattern & 0.024 & 0.011 & 0.029 & 0.024 & 0.012 & 0.043 & 0.028 & 0.012 & 0.022 \\
\hline Med-proxy Pattern & 0.003 & 0.012 & 0.797 & 0.004 & 0.012 & 0.759 & 0.001 & 0.012 & 0.911 \\
\hline Eating-out Pattern & -0.011 & 0.011 & 0.317 & -0.009 & 0.011 & 0.393 & -0.013 & 0.011 & 0.216 \\
\hline $\begin{array}{c}\text { Traditional, vegetarian-alike } \\
\text { Pattern }\end{array}$ & 0.003 & 0.011 & 0.811 & -0.003 & 0.011 & 0.799 & -0.004 & 0.011 & 0.735 \\
\hline $\begin{array}{l}\text { High in unsaturated fats and } \\
\text { fruit juice consumption Pattern } \\
\text { logSGPT / ALT (IU/L) }\end{array}$ & 0.006 & 0.011 & 0.603 & 0.004 & 0.012 & 0.735 & 0.003 & 0.011 & 0.824 \\
\hline Mixed Pattern & 0.052 & 0.014 & $<0.001$ & 0.049 & 0.016 & 0.002 & 0.070 & 0.016 & $<0.001$ \\
\hline Med-proxy Pattern & -0.009 & 0.016 & 0.570 & -0.005 & 0.016 & 0.768 & -0.006 & 0.017 & 0.740 \\
\hline Eating-out Pattern & -0.003 & 0.015 & 0.816 & -0.005 & 0.015 & 0.714 & -0.009 & 0.015 & 0.555 \\
\hline $\begin{array}{c}\text { Traditional, vegetarian-alike } \\
\text { Pattern }\end{array}$ & 0.002 & 0.014 & 0.910 & $<0.001$ & 0.015 & 0.996 & $<0.001$ & 0.015 & 0.978 \\
\hline $\begin{array}{l}\text { High in unsaturated fats and } \\
\text { fruit juice consumption Pattern }\end{array}$ & 0.005 & 0.015 & 0.724 & 0.006 & 0.016 & 0.701 & -0.002 & 0.016 & 0.919 \\
\hline
\end{tabular}

Model 1: Adjusting for age and sex. Model 2: Adjusting for age, sex, smoking habits, physical activity level and logBMI (except for logBMI values). Model 3: Adjusting for age, sex, smoking habits, physical activity level, logBMI, education years, family and professional status.

Nominal associations $(p<0.05)$ are described as follows: consumption of the "Mixed" pattern was correlated with: (a) increased $\log B M I$ values, after adjustment for the confounding factors of all models (Model 1: $\beta=0.019, p<0.001$, Model 2: $\beta=0.017, p<0.001$, Model 3: $\beta=0.015, p$-value $=0.009$; (b) increased levels of body fat percentage, in model $1(\beta=1.179, p=0.003)$; (c) increased levels of the logVisceral fat in Model 1 ( $\beta=0.032$, $p=0.001)$; (d) increased levels of $\log C$ reatinine, in Model 3 ( $\beta=0.012, p=0.048)$ (e) decreased values of HDL cholesterol in Model 1 ( $\beta=-0.020, p<0.006)$; ( $\mathrm{f}$ ) increased levels of $\log$ Triglycerides, in Models $1(\beta=0.038, p=0.007)$ and $3(\beta=0.033, p=0.048)$; $(\mathrm{g})$ increased levels of $\log$ Serum protein in Models $1(\beta=0.004, p=0.036)$ and $3(\beta=0.005, p=0.029)$; and (h) increased levels of $\log$ SGOT / AST (Model 1: $\beta=0.024, p=0.029$, Model 2: $\beta=0.024$, $p=0.043$, Model 3: $\beta=0.028, p$-value $=0.022$ ) and SGPT /ALT (Model 1: $\beta=0.052, p<0.001$, Model 2: $\beta=0.049, p=0.002$, Model 3: $\beta=0.070, p<0.001$ ). The "Med-proxy" pattern was found related with lower values of $\log C$ reatinine, in Model $3(\beta=-0.013, p=0.029)$ and lower values of $\log$ Total Bilirubin, in all models (Model 1: $\beta=-0.036, p=0.025$, Model 2: $\beta=-0.043, p=0.010$, Model 3: $\beta=-0.042, p=0.019)$. The "Traditional, vegetarian-alike" pattern was associated with: (a) reduced levels of body fat, in Models 1 ( $\beta=-0.770$, $p=0.048)$ and $2(\beta=-0.476, p=0.032)$; (b) decreased logVisceral fat values, in Model 2 ( $\beta=-0.008, p=0.032)$; and (c) increased levels of $\log$ HDL cholesterol in models 2 and 3 (Model 2: $\beta=0.017, p=0.017$, Model 3: $\beta=0.016, p=0.039$ ). After evaluation for the adjusted threshold of statistical significance (i.e., $\mathrm{a}=0.05 / 5=0.01$ ), statistically significant associations remained for: (a) the "Mixed" pattern and increased logBMI, body fat and logSGPT/ALT values; (b) the "Mixed" pattern and decreased logHDL cholesterol values; and (c) the "Med-proxy" pattern and decreased levels of logTotal Bilirubin. Further associations are displayed in Appendix A. 
After extracting the dietary patterns, we further explored the effect of their respective adherence to each anthropometric and biochemical biomarker, by separating them into tertiles. As shown in Figures 4-7, increased adherence to the "Mixed" pattern was associated with: (a) increased levels of $\log \mathrm{BMI}(p=0.003)$, (b) decreased levels of $\log$ HDL cholesterol $(p=0.007)$, (c) increased levels of logSerum protein $(p=0.008)$. Additionally, categorization in the higher tertile of the "Med-proxy" pattern was associated with lower levels of $\log$ Creatinine $(p=0.011)$.

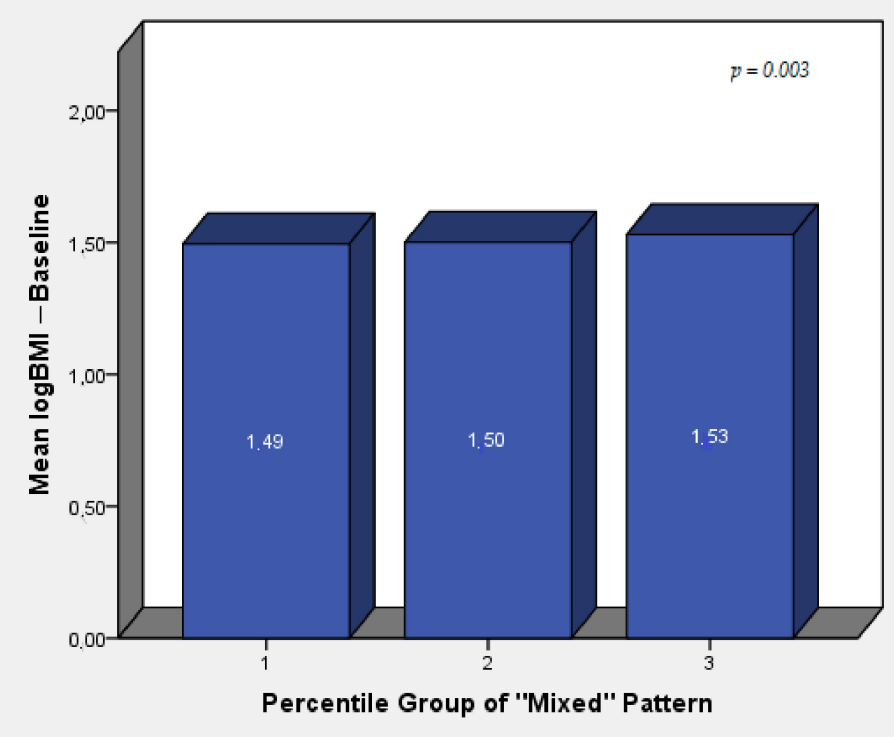

Figure 4. Percentile distribution and associations between the "Mixed" Pattern and logBMI values.

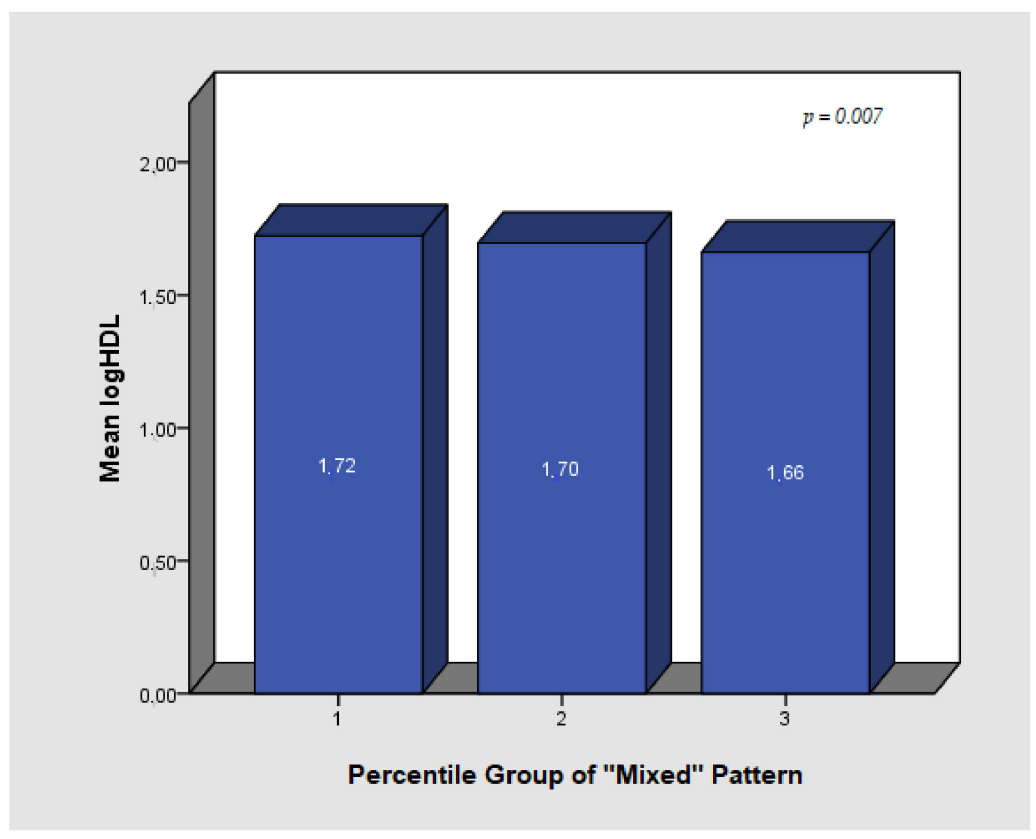

Figure 5. Percentile distribution and associations between the "Mixed" Pattern and logHDL values. 


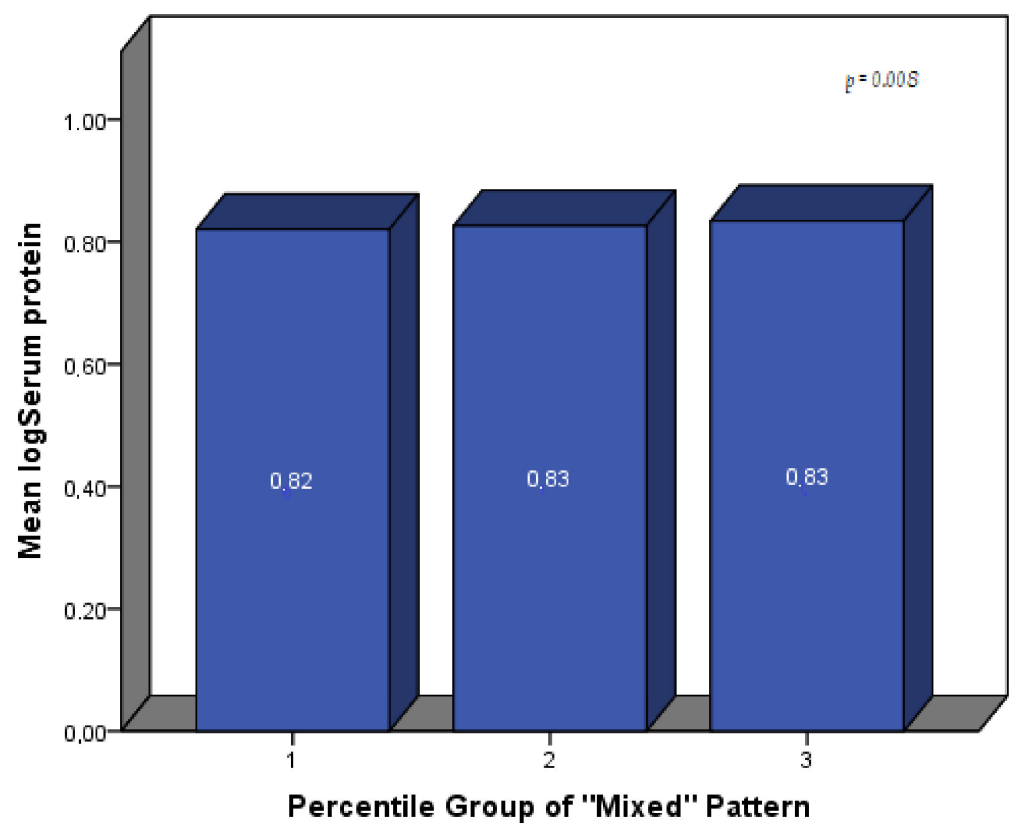

Figure 6. Percentile distribution and associations between the "Mixed" Pattern and logSerum Protein values.

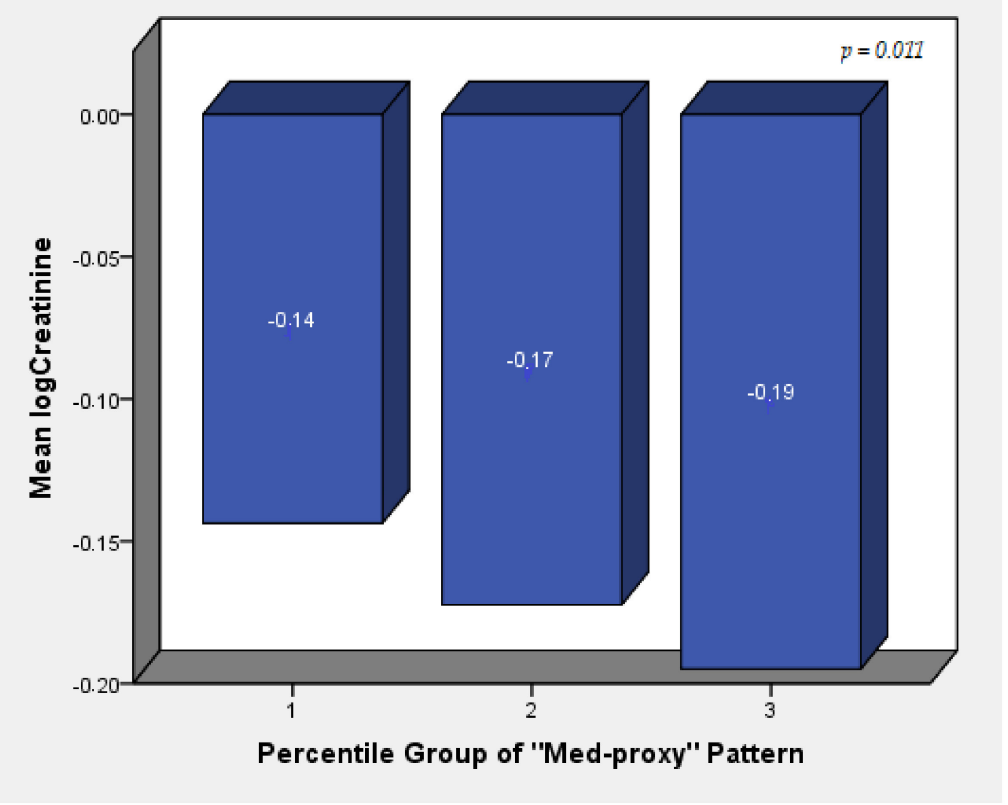

Figure 7. Percentile distribution and associations between the "Med-proxy" Pattern and logCreatinine values.

\subsection{Lifestyle Index (LI) Construction}

Following extraction of the dietary patterns, we examined the potential relations between different sets of variables, in order to evaluate the construction of a Lifestyle Index. We examined potential correlations between the reported lifestyle questionnaire scores, the extracted dietary patterns, and basic aspects, such as smoking and physical activity habits, with anthropometric indices, such as BMI and body fat percentage. All variables under examination were divided into categories, with higher values indicating favorable effects. Continuous and nominal variables displaying positive correlations were dichotomized 
based on the sample's reported median values (attribution of a value of 1 for scores below the sample's median and a value of 2 for scores above the observed median).

Variables displaying statistically significant $(p<0.05)$, positive correlations with either $\log$ BMI of body fat percentage values included: the "Mixed" and "Med-proxy" dietary patterns, the CESD-R-10 depression scale score, and the physical component of the SF-12 scored questionnaire. Subsequently, a Lifestyle Index was created, based on the sum of the aforementioned, dichotomized variables and physical activity categories, as shown in Equation 1. Smoking habits were not included in the Index creation, due to roughly $75 \%$ of our sample being reported as non-smokers. Maximum score of the Lifestyle Index was calculated at the value of 11 . The Index was calculated for 141 participants and the sample presented a median score of 8 and an IQR of 2.

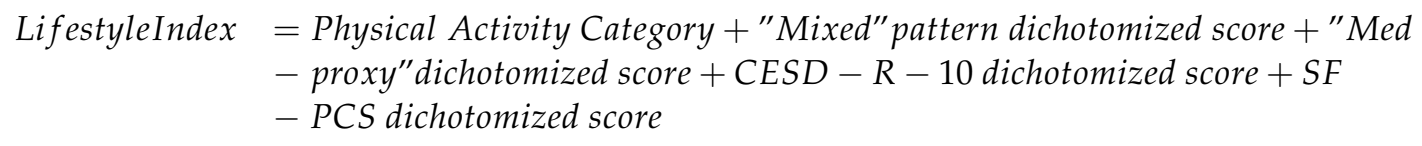

Variables displaying statistically significant $(p<0.05)$, positive correlations with either $\log$ BMI of body fat percentage values included: the "Mixed" and "Med-proxy" dietary patterns, the CESD-R-10 depression scale score and the physical component of the SF-12 scored questionnaire. Subsequently, a Lifestyle Index was created, based on the sum of the aforementioned, dichotomized variables and physical activity categories, as shown in Equation 1. Smoking habits were not included in the Index creation, due to roughly $75 \%$ of our sample being reported as non-smokers.

As depicted in Table 6, the Lifestyle index presented strong associations, including an inverse correlation with: (a) $\log B M I(\beta=-0.010 . p=0.019)$, (b) logFasting glucose (Model 1: $\beta=-0.009, p=0.007$. Model 2: $\beta=-0.007 . p=0.036)$; and (c) logSGPT $(\beta=-0.027$, $p=0.049$ ). When looking at the sex-stratified analyses. Women displayed negative associations between the Index's values and body fat percentage (Model 1: $\beta=-0.911, p=0.030$ ). $\log$ Fasting glucose (Model 1: $\beta=-0.011, p=0.003$. Model 2: $\beta=-0.010, p=0.007$ ). $\operatorname{logSGOT} /$ AST (Model 1: $\beta=-0.017, p=0.026$. Model 2: $\beta=-0.018, p=0.023$ ) and $\operatorname{logSGPT} /$ ALT (Model 1: $\beta=-0.039 . p=0.003$, Model 2: $=-0.038, p=0.005$ ). Men also showed negative associations with $\log$ BMI $(\beta=-0.015, p=0.045)$ and body fat percentage (Model 1: $\beta=-1.123, p=0.048$ ). 
Table 6. Multivariate linear regressions between anthropometric and clinical characteristics and the constructed lifestyle index.

\begin{tabular}{|c|c|c|c|c|c|c|c|c|c|c|c|c|c|c|c|c|c|c|}
\hline & \multicolumn{9}{|c|}{ Model 1} & \multicolumn{9}{|c|}{ Model 2} \\
\hline & \multicolumn{3}{|c|}{ Total * } & \multicolumn{3}{|c|}{ Women } & \multicolumn{3}{|c|}{ Men } & \multicolumn{3}{|c|}{ Total ** } & \multicolumn{3}{|c|}{ Women } & \multicolumn{3}{|c|}{ Men } \\
\hline & $\beta$ & $S E$ & $p$-Value & $\beta$ & $S E$ & $p$-Value & $\beta$ & $S E$ & $p$-Value & $\beta$ & $S E$ & $p$-Value & $\beta$ & $S E$ & $p$-Value & $\beta$ & $S E$ & $p$-Value \\
\hline $\begin{array}{c}\log B M I \\
\text { Lifestyle Index }\end{array}$ & -0.010 & 0.004 & 0.019 & -0.007 & 0.005 & 0.183 & -0.015 & 0.007 & 0.045 & - & - & - & & - & & & - & \\
\hline Body fat $(\%)$ & & & & & & & & & & & & & & & & & & \\
\hline $\begin{array}{c}\text { Lifestyle Index } \\
\text { logFasting glucose }(\mathrm{mg} / \mathrm{dL})\end{array}$ & -0.867 & 0.451 & 0.056 & -0.911 & 0.414 & 0.030 & -1.123 & 0.551 & 0.048 & -0.307 & 0.393 & 0.436 & -0.446 & 0.231 & 0.056 & -0.446 & 0.339 & 0.572 \\
\hline $\begin{array}{l}\text { Lifestyle Index } \\
\log S G O T(I U / L)\end{array}$ & -0.009 & 0.003 & 0.007 & -0.011 & 0.003 & 0.003 & -0.005 & 0.006 & 0.429 & -0.007 & 0.003 & 0.036 & -0.010 & 0.004 & 0.007 & $<0.001$ & 0.006 & 0.953 \\
\hline $\begin{array}{l}\text { Lifestyle Index } \\
\operatorname{LogSGPT}(I U / L)\end{array}$ & -0.006 & 0.009 & 0.534 & -0.017 & 0.007 & 0.026 & 0.017 & 0.020 & 0.397 & -0.006 & 0.010 & 0.518 & -0.018 & 0.008 & 0.023 & 0.015 & 0.021 & 0.484 \\
\hline Lifestyle Index & -0.027 & 0.014 & 0.049 & -0.039 & 0.013 & 0.003 & $<0.001$ & 0.023 & 0.988 & 0.292 & 0.277 & 0.293 & -0.038 & 0.013 & 0.005 & 0.003 & 0.024 & 0.895 \\
\hline
\end{tabular}




\section{Discussion}

The present analyses display the design and the baseline population characteristics and dietary habits of the iMPROVE study. Overall, our baseline sample of 202 volunteers displayed satisfactory levels of lifestyle quality, with the majority of participants not reporting depression symptoms or heavily disrupted sleep quality.

Five dietary patterns were identified, including: (a) a "Mixed" pattern; (b) a pattern including food groups similar to those of the Mediterranean diet, entitled "Med-proxy" pattern; (c) the "Eating-out" pattern consisting of food combinations usually found in restaurants or fast-food environments (i.e., pies); (d) the "Traditional, vegetarian-alike" pattern, characterized by plant-based, Greek, traditional recipes; and (e) the "High in unsaturated fats and fruit juice consumption" pattern, including foods groups with high unsaturated fats and magnesium content (i.e., small fish and nuts) and highlighting representative habits of healthy snacking across Greek adults (i.e., olives, nuts and fruit juice). Interestingly, while the "Mixed" pattern included a vast majority of processed foods with added sugars and high fat content (i.e., chocolate, croissants, tray sweets, soft drinks, chips, seed oil, margarine, and butter), it was also characterized by light products and chicken and potatoes' consumption. This can be potentially attributed to the representative consumption of specific food groups by overweight and obese Greeks, who tend to adhere to short-term, self-imposed attempts to follow a more balanced diet. The latter do not result in successful weight management and/or weight loss efforts, but are exactly characterized by increased consumption of light products and simple food combinations, such as chicken and potatoes. The "Med-proxy" and the "Traditional, vegetarian-alike" patterns are representative of the dietary habits of the Greek population, evidently influenced by the Mediterranean diet and its increased content in fruit, vegetables, and legumes. Apparently, due to its high sugar and fat content, the "Mixed" pattern was associated with higher levels of anthropometric and biochemical characteristics. On the other hand, the plant-based, traditional recipes presented negative associations with body fat and positive relations with increased levels of HDL cholesterol. We further evaluated the within-group tertile categorization of adherence to each pattern, showing that higher tertiles were related to stronger associations for specific patterns, such as the positive relationship between adherence to the "Mixed" pattern and $\log B M I$ levels and the negative relationship between the increased adherence to the same pattern and $\log H D L$ values.

The concept of obese adults and the effect of dietary intake in the formation of their cardiometabolic profile display great interest, with current literature to be reporting similar findings to the ones outlined in the present study. Interestingly, the majority of studies aiming at identifying dietary patterns in overweight/obese populations, usually provide results for dietary habits adhering to the Western diet (including food groups with increased content of processed foods and/or foods in high fat and sugar content) or to a more balanced dietary pattern including fruit and vegetables, relating to higher and lower values of BMI, respectively [2]. Such patterns may include food combinations each time representative of the region of living, while maintaining a strong influence of the dietary habits and combinations usually found in the Western and/or the Mediterranean diet. A 2021 study by Saghafi-Asi et al. investigating the relationship between dietary patterns and biochemical biomarkers of 151 healthy obese Iranian adults, also underlined a positive association between a "Western" dietary pattern with high fat and sugar content and BMI and body fat levels [22]. Additionally, a different study in Romanian obese adults also underlined the identification of a "high meat/high fat", a "Western," and a "Prudent" pattern [23]. Similar findings were reported in a cohort of 410 Polish participants of a case-control study, where adherence to a pattern influenced by the Western one was related with higher levels of fat tissue and waist circumference, in contrast with the adherence to a "Healthy" pattern [24]. In their 2019 longitudinal study, Neri-Sanchez et al. also underlined the positive association between adherence to a "Risky" dietary pattern, including high fat and high sugar content, with the presence of central obesity in Mexican adults [25]. A different pattern consisting of poultry, vegetables, red meat, and red meat products, 
among others, was also associated with obesity in male, Chinese adults, in a 2021 study of 1739 adults by Wang et al. [26].

Additionally, a different cross-sectional study of our group identified similar associations between dietary patterns and biochemical biomarkers in the adults of the POMAK population. More specifically, the dietary pattern including increased consumption of products high in sugars was related to low levels of HDL cholesterol [27]. Similar trends were also noted when investigating the dietary patterns of adolescent populations, where a dietary pattern with high protein and animal fat content was associated with elevated levels of $\log$ BMI and logTriglycerides, in French teenagers [28].

Furthermore, the development of the novel Lifestyle Index using the data deriving from the study sample, allowed for further investigation of the quality of life characteristics on the anthropometric and biochemical indices. Consisting of five variables, including two of the present dietary patterns extracted, the Index displayed negative associations with $\log \mathrm{BMI}$ and body fat levels, as well as levels of the log-transformed variables of fasting glucose, SGOT, and SGPT. Thus, LI confirmed that higher quality of dietary intake and higher levels of physical activity reduced depression symptoms and improved self-reported conception of health status and may display a protective effect on body composition, as well as a favorable influence on improved glycemic profile.

Overall, development of lifestyle indices as a means of quantifying and evaluating the potential influence of specific lifestyle aspects on body weight is mounting, as analyzed in the beginning of the paper, lifestyle indices can also incorporate dietary information via calculation of diet quality indices. A 2017 systematic review of 34 studies by Asghari et al., sought to investigate the effect of diet quality indices in obesity-related traits, showing that Healthy Eating Index (HEI) displayed an inverse association with obesity. The same review also concluded that different dietary scores, in general, did not efficiently assess diet quality, with most significant findings being presented in populations of the United States [29]. Furthermore, different research groups have investigated the effect of lifestyle characteristics, such as sedentary behavior and screen-time, in adolescent populations [30-32]. In adults, current research refers to potential associations between constructed lifestyle indices and specific diseases or disease-related outcomes, namely cardiovascular disease [8], cancer [33], and type 2 diabetes [34]. Lenz et al., showed that creation of a Lifestyle Index for evaluation of life quality in adults at risk for cardiovascular disease can be a useful tool [35]. Furthermore, in a similar effort to evaluate the lifestyle aspects and weight characteristics, Roda et el in 2016, also investigated the potential effect of sleep qualities, screen time, and dietary intake, among others, highlighting a strong positive association between sedentary behavior and overweight [36].

A major advantage of the present study is the use of the online assessment tool, as a means enabling long-distance communication and monitoring, during the time of social distancing, due to the novel coronavirus disease 19 (COVID-19) pandemic. On the other hand, limitations of the present study include: (a) the substantial impact of the COVID-19 pandemic on volunteer recruitment rates. More specifically, conduct of the study's volunteer recruitment took place exactly in the midst of the COVID-19 pandemic, which resulted in a limited recruitment capacity due to: (a) The social-distancing protocols implemented in recruitment sites, properly adhering to the state guidelines, which resulted in a restricted number of participants visiting the premises; (b) the limited expression of interest for participation in the study, due to fear of in-person meetings and subsequent spread of the COVID-19 disease; (c) the long-distance maintenance of an increased adherence rate to the proposed diets, due to the extended time period between the in-person follow-up meetings; and (d) the proper use of the online assessment tool by older adults who had both limited access and knowledge on the use of state-of-the-art technological devices and online tools.

\section{Conclusions}

Results from the present study suggest that the iMPROVE overweight and obese, adult cohort displays a satisfactory level of lifestyle characteristics and dietary behaviors 
representative of the overweight and obese Greek population. Assessment of the constructed Lifestyle Index, further solidifies the validity of our findings, highlighting the protective effect of increased lifestyle quality in the formation of elevated body weight. In this spectrum, the findings of the present paper enhance the understanding of overweight/obesity lifestyle determinants in our sample population and lay the ground for the next analysis steps of the iMPROVE study, which focus on assessing the impact of the proposed intervention and the role of candidate genes in various weight-related indices. Assessment of the holistic interplay of gene-lifestyle interactions is of vital importance for the in-depth understanding of nutrigenetic influences in weight loss, as well as in the general context of weight management and/or weight loss maintenance.

Author Contributions: Conceptualization, G.V.D. and A.C.K.; methodology, G.V.D. and A.C.K.; software, I.V.; validation, M.K. and I.P.K.; formal analysis, M.K. and I.P.K.; investigation, M.K., I.P.K., E.A.K.; resources, G.V.D.; data curation, M.K., E.A.K., S.L.; writing—original draft preparation, M.K., I.P.K.; writing—review and editing, I.P.K., M.K.; visualization, G.V.D. and A.C.K.; supervision, G.V.D., A.C.K.; project administration, G.V.D.; funding acquisition, G.V.D. All authors have read and agreed to the published version of the manuscript.

Funding: "This research is co-financed by Greece and the European Union (European Social FundESF) through the Operational Programme «Human Resources Development, Education and Lifelong Learning 2014-2020" in the context of the project " "SUPPORT OF YOUNG RESEARCHERS - CALL B', ESPA 2014-2020": 61109 " (MIS 5048457)."

Institutional Review Board Statement: The study was conducted according to the guidelines of the Declaration of Helsinki, and approved by the Research Ethics Committee of Harokopio University of Athens (Protocol Number: 1800/13-06-2019).

Informed Consent Statement: Informed consent was obtained from all subjects involved in the study.

Data Availability Statement: The data presented in this study are available on request from the corresponding author. The data are not publicly available due to participants' privacy and ethical restrictions.

Acknowledgments: The iMPROVE study was conducted at the premises of Harokopio University of Athens. The authors would like to sincerely thank all professionals and students of the Department of Nutrition and Dietetics of Harokopio University of Athens, for their valuable help and contribution concerning the participants' recruitment, monitoring, and the conduct of all in-person meetings. The authors address their sincere gratitude to all the participants and volunteers of the iMPROVE study, for their valuable and fruitful cooperation.

Conflicts of Interest: The authors declare no conflict of interest.

\section{Appendix A}

Continuation of Table 5, with analyses of variables that did not display statistically significant changes (to be uploaded as Table A1).

Table A1. Multivariate linear regressions between the extracted dietary patterns and indices of anthropometric and biochemical characteristics.

\begin{tabular}{|c|c|c|c|c|c|c|c|c|c|}
\hline & \multicolumn{3}{|c|}{ Model 1} & \multicolumn{3}{|c|}{ Model 2} & \multicolumn{3}{|c|}{ Model 3} \\
\hline & $\beta$ & $S E$ & $p$-Value & $\beta$ & $S E$ & $p$-Value & $\beta$ & $S E$ & $p$-Value \\
\hline logGlucose (mg/dL) & & & & & & & & & \\
\hline Mixed Pattern & 0.006 & 0.004 & 0.127 & 0.001 & 0.004 & 0.803 & 0.001 & 0.004 & 0.803 \\
\hline Med-proxy Pattern & $<0.001$ & 0.004 & 0.980 & 0.002 & 0.004 & 0.560 & 0.002 & 0.004 & 0.560 \\
\hline Eating-out Pattern & 0.002 & 0.004 & 0.635 & 0.001 & 0.004 & 0.862 & 0.001 & 0.004 & 0.862 \\
\hline $\begin{array}{c}\text { Traditional, vegetarian-alike } \\
\text { Pattern }\end{array}$ & 0.003 & 0.004 & 0.462 & 0.001 & 0.004 & 0.871 & 0.001 & 0.004 & 0.871 \\
\hline $\begin{array}{c}\text { High in unsaturated fats Pattern } \\
\log \text { Urea }(\mathrm{mg} / \mathrm{dL})\end{array}$ & -0.003 & 0.004 & 0.380 & -0.005 & 0.004 & 0.222 & -0.005 & 0.004 & 0.222 \\
\hline Mixed Pattern & 0.004 & 0.007 & 0.566 & 0.002 & 0.008 & 0.814 & 0.001 & 0.009 & 0.932 \\
\hline
\end{tabular}


Table A1. Cont.

\begin{tabular}{|c|c|c|c|c|c|c|c|c|c|}
\hline & \multicolumn{3}{|c|}{ Model 1} & \multicolumn{3}{|c|}{ Model 2} & \multicolumn{3}{|c|}{ Model 3} \\
\hline & $\beta$ & $S E$ & $p$-Value & $\beta$ & $S E$ & $p$-Value & $\beta$ & $S E$ & $p$-Value \\
\hline Med-proxy Pattern & 0.010 & 0.008 & 0.204 & 0.012 & 0.008 & 0.145 & 0.012 & 0.009 & 0.196 \\
\hline Eating-out Pattern & -0.005 & 0.007 & 0.498 & -0.005 & 0.007 & 0.467 & -0.008 & 0.008 & 0.349 \\
\hline $\begin{array}{c}\text { Traditional, vegetarian-alike } \\
\text { Pattern }\end{array}$ & $<0.001$ & 0.007 & 0.989 & -0.001 & 0.008 & 0.847 & -0.004 & 0.008 & 0.622 \\
\hline $\begin{array}{c}\text { High in unsaturated fats Pattern } \\
\operatorname{logUric} \text { Acid }(\mathrm{mg} / \mathrm{dL})\end{array}$ & -0.002 & 0.007 & 0.758 & -0.002 & 0.008 & 0.791 & -0.004 & 0.008 & 0.637 \\
\hline Mixed Pattern & 0.006 & 0.006 & 0.377 & -0.006 & 0.007 & 0.361 & -0.004 & 0.007 & 0.628 \\
\hline Med-proxy Pattern & -0.004 & 0.007 & 0.585 & -0.001 & 0.007 & 0.854 & $<0.001$ & 0.007 & 0.963 \\
\hline Eating-out Pattern & 0.003 & 0.006 & 0.603 & 0.002 & 0.006 & 0.749 & -0.002 & 0.006 & 0.805 \\
\hline $\begin{array}{c}\text { Traditional, vegetarian-alike } \\
\text { Pattern }\end{array}$ & -0.002 & 0.006 & 0.739 & -0.004 & 0.006 & 0.506 & -0.004 & 0.007 & 0.502 \\
\hline $\begin{array}{l}\text { High in unsaturated fats Pattern } \\
\text { Total Cholesterol }(\mathrm{mg} / \mathrm{dL})\end{array}$ & -0.006 & 0.006 & 0.336 & -0.006 & 0.006 & 0.358 & -0.007 & 0.007 & 0.331 \\
\hline Mixed Pattern & -0.259 & 2.402 & 0.914 & 1.283 & 2.575 & 0.619 & 0.922 & 2.915 & 0.752 \\
\hline Med-proxy Pattern & -3.271 & 2.534 & 0.198 & -2.864 & 2.622 & 0.276 & -3.629 & 2.860 & 0.206 \\
\hline Eating-out Pattern & -0.080 & 2.394 & 0.973 & -0.274 & 2.414 & 0.910 & -0.631 & 2.601 & 0.809 \\
\hline $\begin{array}{c}\text { Traditional, vegetarian-alike } \\
\text { Pattern }\end{array}$ & 2.297 & 2.297 & 0.323 & 3.766 & 2.463 & 0.128 & 4.722 & 2.618 & 0.073 \\
\hline $\begin{array}{l}\text { High in unsaturated fats Pattern } \\
\operatorname{logLDL} \text { Cholesterol (mg/dL) }\end{array}$ & -0.202 & 2.445 & 0.934 & 0.819 & 2.519 & 0.746 & 0.103 & 2.711 & 0.970 \\
\hline Mixed Pattern & -0.007 & 0.010 & 0.492 & 0.005 & 0.010 & 0.613 & 0.002 & 0.011 & 0.878 \\
\hline Med-proxy Pattern & -0.008 & 0.010 & 0.430 & -0.005 & 0.010 & 0.642 & -0.008 & 0.011 & 0.491 \\
\hline Eating-out Pattern & -0.003 & 0.010 & 0.751 & -0.004 & 0.009 & 0.659 & -0.006 & 0.010 & 0.557 \\
\hline $\begin{array}{c}\text { Traditional, vegetarian-alike } \\
\text { Pattern }\end{array}$ & -0.006 & 0.009 & 0.539 & 0.002 & 0.010 & 0.816 & 0.005 & 0.010 & 0.625 \\
\hline $\begin{array}{l}\text { High in unsaturated fats Pattern } \\
\log A \operatorname{lbumin}(\mathrm{g} / \mathrm{dL})\end{array}$ & -0.010 & 0.010 & 0.321 & -0.003 & 0.010 & 0.755 & -0.003 & 0.011 & 0.746 \\
\hline Mixed Pattern & 0.002 & 0.004 & 0.665 & 0.003 & 0.004 & 0.412 & 0.003 & 0.002 & 0.199 \\
\hline Med-proxy Pattern & -0.002 & 0.004 & 0.691 & -0.002 & 0.004 & 0.584 & 0.002 & 0.002 & 0.289 \\
\hline Eating-out Pattern & $<0.001$ & 0.004 & 0.904 & 0.001 & 0.004 & 0.759 & $<0.001$ & 0.002 & 0.977 \\
\hline $\begin{array}{c}\text { Traditional, vegetarian-alike } \\
\text { Pattern }\end{array}$ & 0.003 & 0.004 & 0.368 & 0.003 & 0.004 & 0.508 & 0.003 & 0.002 & 0.115 \\
\hline High in unsaturated fats Pattern & -0.002 & 0.004 & 0.606 & -0.003 & 0.004 & 0.441 & 0.001 & 0.002 & 0.733 \\
\hline
\end{tabular}

Model 1: Adjusting for age and sex. Model 2: Adjusting for age, sex, smoking habits, physical activity level, and logBMI (except for logBMI

values). Model 3: Adjusting for age, sex, smoking habits, physical activity level, logBMI, education years, family, and professional status.

\section{References}

1. Eurostat. Over Half of Adults in the EU Are Overweight. 2021. Available online: https:/ / ec.europa.eu/eurostat/web/productseurostat-news /-/ddn-20210721-2 (accessed on 3 August 2021).

2. $\mathrm{Mu}, \mathrm{M} . ; \mathrm{Xu}, \mathrm{L} .-\mathrm{F} . ; \mathrm{Hu}, \mathrm{N} . ; \mathrm{Wu}, \mathrm{J} . ;$ Bai, M.-J. Dietary Patterns and Overweight/Obesity: A Review Article. Iran. J. Public Health 2017, 46, 869-876. [PubMed]

3. Cena, H.; Calder, P.C. Defining a Healthy Diet: Evidence for the Role of Contemporary Dietary Patterns in Health and Disease. Nutrients 2020, 12, 334. [CrossRef] [PubMed]

4. Stelmach-Mardas, M.; Rodacki, T.; Dobrowolska-Iwanek, J.; Brzozowska, A.; Walkowiak, J.; Wojtanowska-Krosniak, A.; Zagrodzki, P.; Bechthold, A.; Mardas, M.; Boeing, H. Link between Food Energy Density and Body Weight Changes in Obese Adults. Nutrients 2016, 8, 229. [CrossRef] [PubMed]

5. Li, Y.; Lv, M.-R.; Wei, Y.-J.; Sun, L.; Zhang, J.-X.; Zhang, H.-G.; Li, B. Dietary patterns and depression risk: A meta-analysis. Psychiatry Res. 2017, 253, 373-382. [CrossRef] [PubMed]

6. Godos, J.; Grosso, G.; Castellano, S.; Galvano, F.; Caraci, F.; Ferri, R. Association between diet and sleep quality: A systematic review. Sleep Med. Rev. 2021, 57, 101430. [CrossRef] [PubMed]

7. Mamalaki, E.; Poulimeneas, D.; Kosmidis, M.H.; Yannakoulia, M. Mediterranean lifestyle patterns are associated with cognition in older adults. Lifestyle Med. 2021, 2, e30. [CrossRef]

8. Barbaresko, J.; Rienks, J.; Nöthlings, U. Lifestyle Indices and Cardiovascular Disease Risk: A Meta-Analysis. Am. J. Prev. Med. 2018, 55, 555-564. [CrossRef] [PubMed] 
9. Navarro, P.; Mehegan, J.; Murrin, C.M.; Kelleher, C.C.; Phillips, C.M.; Lifeways Cross Generation Cohort Study. Associations between a maternal healthy lifestyle score and adverse offspring birth outcomes and childhood obesity in the Lifeways CrossGeneration Cohort Study. Int. J. Obes. 2020, 44, 2213-2224. [CrossRef]

10. Liao, J.; Muniz-Terrera, G.; Scholes, S.; Hao, Y.; Chen, Y.-M. Lifestyle index for mortality prediction using multiple ageing cohorts in the USA, UK and Europe. Sci. Rep. 2018, 8, 6644. [CrossRef]

11. NIH; NHLBI Obesity Education Initiative. Clinical Guidelines on the Identification, Evaluation, and Treatment of Overweight and Obesity in Adults. Obes. Educ. Initiat. 1998, 6 (Suppl. S2), 51S-209S. Available online: http:/ / www.nhlbi.nih.gov/guidelines/ obesity /ob_gdlns.pdf (accessed on 10 September 2021).

12. Panagiotakos, D.B.; Pitsavos, C.; Arvaniti, F.; Stefanadis, C. Adherence to the Mediterranean food pattern predicts the prevalence of hypertension, hypercholesterolemia, diabetes and obesity, among healthy adults; the accuracy of the MedDietScore. Prev. Med. 2007, 44, 335-340. [CrossRef] [PubMed]

13. Radloff, L.S. The CES-D scale: A self-report depression scale for research in the general population. Appl. Psychol. Meas. 1977, 1, 385-401. Available online: https://www.brandeis.edu/roybal/docs/CESD-R_Website_PDF.pdf (accessed on 1 September 2021). [CrossRef]

14. Ware, J.E.; Kosinski, M.; Keller, S. A 12-Item Short-Form Health Survey: Construction of Scales and Preliminary Tests of Reliability and Validity. Med. Care 1996, 34, 220-233. Available online: http://www.jstor.org/stable/3766749 (accessed on 1 September 2021). [CrossRef]

15. Soldatos, C.R.; Dikeos, D.G.; Paparrigopoulos, T.J. Athens Insomnia Scale: Validation of an instrument based on ICD-10 criteria. J. Psychosom. Res. 2000, 48, 555-560. [CrossRef]

16. Bountziouka, V.; Bathrellou, E.; Giotopoulou, A.; Katsagoni, C.N.; Bonou, M.; Vallianou, N.; Barbetseas, J.; Avgerinos, P.; Panagiotakos, D. Development, repeatability and validity regarding energy and macronutrient intake of a semi-quantitative food frequency questionnaire: Methodological considerations. Nutr. Metab. Cardiovasc. Dis. 2012, 22, 659-667. [CrossRef] [PubMed]

17. International Physical Activity Questionnaire (IPAQ). Revised in 2013. Available online: https://sites.google.com/site/theipaq/ questionnaire_links (accessed on 1 September 2021).

18. ThermoFisher Scientific. iPrep ${ }^{\mathrm{TM}}$ PureLink ${ }^{\mathrm{TM}}$ gDNA Blood Kit. Available online: https://www.thermofisher.com/order/catalog/ product/IS10005\#/IS10005 (accessed on 30 July 2021).

19. ThermoFisher Scientific. Axiom ${ }^{\mathrm{TM}}$ Precision Medicine Diversity Array Plus Kit, 96-Format. Available online: https://www. thermofisher.com/order/catalog/product/951961\#/951961 (accessed on 30 July 2021).

20. IBM Support. SPSS Statistics 23.0 Now Available for Download. Available online: https://www.ibm.com/support/pages/spssstatistics-230-now-available-download (accessed on 7 January 2021).

21. The R Project for Statistical Computing. Last Modified in 2020. Available online: https:/ /www.r-project.org/ (accessed on 5 January 2021).

22. Saghafi-Asl, M.; Mirmajidi, S.; Jafarabadi, M.A.; Vahid, F.; Shivappa, N.; Hébert, J.R.; Attari, V.E. The association of dietary patterns with dietary inflammatory index, systemic inflammation, and insulin resistance, in apparently healthy individuals with obesity. Sci. Rep. 2021, 11, 7515. [CrossRef] [PubMed]

23. Roman, G.; Rusu, A.; Graur, M.; Creteanu, G.; Morosanu, M.; Radulian, G.; Amorin, P.; Timar, R.; Pircalaboiu, L.; Bala, C. Dietary Patterns and Their Association with Obesity: A Cross-Sectional Study. Acta Endocrinol. 2019, 15, 86-95. [CrossRef] [PubMed]

24. Malinowska, A.; Młodzik-Czyżewska, M.; Chmurzynska, A. Dietary patterns associated with obesity and overweight: When should misreporters be included in analysis? Nutrition 2020, 70, 110605. [CrossRef] [PubMed]

25. Neri-Sánchez, M.; Martínez-Carrillo, B.E.; Valdés-Ramos, R.; Soto-Piña, A.E.; Vargas-Hernández, J.A.; Benítez-Arciniega, A.D. Dietary patterns, central obesity and serum lipids concentration in Mexican adults. Nutr. Hosp. 2019, 36, 109-117. [CrossRef]

26. Wang, Y.-Y.; Tian, T.; Pan, D.; Zhang, J.-X.; Xie, W.; Wang, S.-K.; Xia, H.; Dai, Y.; Sun, G. The relationship between dietary patterns and overweight and obesity among adult in Jiangsu Province of China: A structural equation model. BMC Public Health 2021, 21, 1225. [CrossRef]

27. Farmaki, A.-E.; Rayner, N.W.; Kafyra, M.; Matchan, A.; Ntaoutidou, K.; Feritoglou, P.; Athanasiadis, A.; Gilly, A.; Mamakou, V.; Zengini, E.; et al. A Dietary Pattern with High Sugar Content Is Associated with Cardiometabolic Risk Factors in the Pomak Population. Nutrients 2019, 11, 3043. [CrossRef]

28. Kafyra, M.; Kalafati, I.P.; Kumar, S.; Kontoe, M.S.; Masson, C.; Siest, S.; Dedoussis, G.V. Dietary Patterns, Blood Pressure and the Glycemic and Lipidemic Profile of Two Teenage, European Populations. Nutrients 2021, 13, 198. [CrossRef]

29. Asghari, G.; Mirmiran, P.; Yuzbashian, E.; Azizi, F. A systematic review of diet quality indices in relation to obesity. Br. J. Nutr. 2017, 117, 1055-1065. [CrossRef]

30. Ntalla, I.; Yannakoulia, M.; Dedoussis, G.V. An Overweight Preventive Score associates with obesity and glycemic traits. Metabolism 2016, 65, 81-88. [CrossRef] [PubMed]

31. Kosti, R.I.; Panagiotakos, D.B.; Mariolis, A.; Zampelas, A.; Athanasopoulos, P.; Tountas, Y. The Diet-Lifestyle Index evaluating the quality of eating and lifestyle behaviours in relation to the prevalence of overweight/obesity in adolescents. Int. J. Food Sci. Nutr. 2009, 60 (Suppl. S3), 34-47. [CrossRef] [PubMed]

32. Kontogianni, M.D.; Farmaki, A.-E.; Vidra, N.; Sofrona, S.; Magkanari, F.; Yannakoulia, M. Associations between Lifestyle Patterns and Body Mass Index in a Sample of Greek Children and Adolescents. J. Am. Diet. Assoc. 2010, 110, 215-221. [CrossRef] [PubMed] 
33. McKenzie, F.; Biessy, C.; Ferrari, P.; Freisling, H.; Rinaldi, S.; Chajès, V.; Dahm, C.; Overvad, K.; Dossus, L.; Lagiou, P.; et al. Healthy Lifestyle and Risk of Cancer in the European Prospective Investigation into Cancer and Nutrition Cohort Study. Medicine 2016, 95, e2850. [CrossRef] [PubMed]

34. Zhang, Y.; Pan, X.-F.; Chen, J.; Xia, L.; Cao, A.; Zhang, Y.; Wang, J.; Li, H.; Yang, K.; Guo, K.; et al. Combined lifestyle factors and risk of incident type 2 diabetes and prognosis among individuals with type 2 diabetes: A systematic review and meta-analysis of prospective cohort studies. Diabetologia 2019, 63, 21-33. [CrossRef] [PubMed]

35. Lenz, T.L.; Gillespie, N.D.; Skradski, J.J.; Viereck, L.K.; Packard, K.A.; Monaghan, M.S. Development of a Composite Lifestyle Index and Its Relationship to Quality of Life Improvement: The CLI Pilot Study. ISRN Prev. Med. 2013, 2013, 481030. [CrossRef]

36. Roda, C.; Charreire, H.; Feuillet, T.; MacKenbach, J.D.; Compernolle, S.; Glonti, K.; Bárdos, H.; Rutter, H.; McKee, M.; Brug, J.; et al. Lifestyle correlates of overweight in adults: A hierarchical approach (the SPOTLIGHT project). Int. J. Behav. Nutr. Phys. Act. 2016, 13, 114. [CrossRef] 